\title{
Usos del pasado y confiabilidad de las fuentes: Antoine-Joseph Pernety y la disputa sobre la naturaleza de América en el siglo XVIII
}

Uses of the past and reliability of the sources: Antoine-Joseph Pernety and the dispute over the nature of America

\section{Carolina Martínez}

\section{OpenEdition}

\section{Journals}

\section{Electronic version}

URL: http://journals.openedition.org/corpusarchivos/1449

DOI: $10.4000 /$ corpusarchivos. 1449

ISSN: $1853-8037$

\section{Publisher}

Diego Escolar

\section{Electronic reference}

Carolina Martínez, « Usos del pasado y confiabilidad de las fuentes: Antoine-Joseph Pernety y la disputa sobre la naturaleza de América en el siglo XVIII », Corpus [En línea], Vol 5, No 2 | 2015, Publicado el 16 diciembre 2015, consultado el 20 abril 2019. URL : http://journals.openedition.org/ corpusarchivos/1449; DOI : 10.4000/corpusarchivos.1449

This text was automatically generated on 20 April 2019. 


\section{Usos del pasado y confiabilidad de las fuentes: Antoine-Joseph Pernety y la disputa sobre la naturaleza de América en el siglo XVIII}

Uses of the past and reliability of the sources: Antoine-Joseph Pernety and the dispute over the nature of America

Carolina Martínez

\section{EDITOR'S NOTE}

Fecha de recepción del original: 15/09/2014

Fecha de aceptación para publicación: 17/05/2015

\section{Acerca del debate en torno a la naturaleza de América: reinsertando una obra en su contexto de producción}

1 Todo estudio pormenorizado de la obra de Antoine-Joseph Pernety conlleva indagar, sin duda, en torno al debate sobre la naturaleza de América que se desarrolló en Europa en el último cuarto del siglo XVIII. En efecto, las tres obras que el benedictino publicó en el breve período que transcurre entre 1769 y 1771 constituyen una valiosa fuente de información acerca de los puntos en discusión, las herramientas argumentativas y las diversas posturas en torno al estatus del Nuevo Mundo que fueron debatidas en el período mencionado (Podgorny, Penhos, Navarro Floria 2009, p. 76). Es por ello que, más allá de presentarse aquí un fragmento de su Dissertation sur l'Amérique et les Américains contre les Recherches philosophiques de M. de $P^{* * *}$ (1770), en función de reconstruir el contexto en el 
que la obra fue producida deberá indagarse en primer lugar en torno al vínculo de Pernety con la figura del philosophe holandés Cornelius De Pauw, quien devino en su principal interlocutor en la contienda sobre la naturaleza del Nuevo Mundo y contra los postulados del cual el benedictino articuló su propia defensa de América. Por otra parte, también deberán ser tomadas en consideración las impresiones sobre América que Pernety plasmara tanto en su Histoire d'un voyage aux Îles Malouines (1770) como en su Examen des Recherches philosophiques sur l'Amérique et les Américains, et de la Défense de cet ouvrage, obra con la cual en 1771 el benedictino dio por terminada su participación en el debate sobre la naturaleza de América.

2 A su vez, resulta necesario comprender que aquella polémica sobre la naturaleza del Nuevo Mundo que involucró tanto a filósofos como a viajeros ilustrados, a ambos lados del Atlántico (Cicerchia 2000, p. 3), ${ }^{1}$ tuvo lugar dentro de un contexto sociopolítico mayor signado por dos procesos concomitantes. Por un lado, el debate en torno a la naturaleza de América ocurrió en un período en el que las potencias rivales a España comenzaron a disputar con mayor fuerza el control de esta última sobre sus dominios americanos. Esto llevó, por su parte, al celoso afán de la monarquía ibérica por proteger sus conquistas de toda penetración extranjera (Pratt 1992, pp. 16-18).

3 Por el otro, las propias transformaciones en las prácticas instrumentales de los viajeros científicos y filósofos naturales ocurridas entre mediados del siglo XVII y fines del siglo XVIII (Bourguet, Licoppe 1997, p. 1115, Valverde Pérez 2007, p. 15) también deberían tomarse en cuenta al momento de reconstruir el contexto en el que tuvo lugar el debate. En efecto, con la publicación en 1735 del Systema Naturae del naturalista sueco Carlos Linneo comenzaba a pensarse ya en un sistema de clasificación universal que permitiera incorporar al saber europeo todas las plantas del mundo, descubiertas y por descubrir. Este como otros cambios en las formas de hacer y pensar la ciencia fueron a su vez parte de intereses políticos, económicos y religiosos. Tal como ha señalado Mauricio Nieto Olarte (2003) para el caso de América en el siglo XVIII, la prácticas científicas constituyeron importantes formas de control tanto de la naturaleza como de la sociedad, por lo que "el proyecto de un inventario del mundo no se puede separar de la conquista y el control de buena parte del planeta por parte de las naciones más fuertes de Europa" (Nieto Olarte 2003, p. 240).

4 Sucedió entonces que fundamentándose en la redefinición de las prácticas y del estatuto del saber científico ocurridas en la Europa ilustrada, y con la clara intención de penetrar territorio americano, a lo largo del siglo XVIII las potencias rivales a la monarquía ibérica cuestionaron el grado de conocimiento que, hasta entonces, la misma había detentado sobre sus propios dominios coloniales. De tal forma, más allá de que en este mismo período comenzara a gestarse en España una comunidad científica de nuevo tipo (Valverde 2007, p. 19), en su artículo sobre "España", publicado en la Encyclopédie méthodique (1782) de Panckoucke, Masson de Morvilliers sostenía, por ejemplo, que la Corona española no había hecho ninguna contribución a la generación de conocimiento. ${ }^{2}$ Esto no implicaba, sin embargo, que con miras a alejarse de la visión estigmatizada con la que sus rivales, Inglaterra y Francia, pretendían denostarla y justificar así su propio accionar en estas tierras, Felipe $\mathrm{V}$ no hubiese permitido la realización de viajes con fines científicos en alianza con otras naciones. ${ }^{3}$

5 Más allá de esto último, es en este contexto global de emergencia de un nuevo proyecto de "conciencia planetaria", con foco en la exploración del interior de los continentes (Pratt 1992, p. 9), ${ }^{4}$ que debe entenderse el desarrollo del debate en torno a la naturaleza 
de América y los intereses de cada una de las partes en juego. De allí que el presente artículo tenga por objetivo analizar el contexto de producción y los mecanismos a través de los cuales Pernety articuló su defensa de América contra las invectivas de De Pauw, deteniéndose particularmente en un fragmento de su Disertación sobre América y los americanos, publicado por primera vez en 1770 y traducido aquí por primera vez al castellano. La importancia del fragmento seleccionado radica no solamente en el hecho de que condensa los postulados y principales argumentaciones de Pernety en su defensa de América, sino también en las abundantes referencias a relatos, experiencias y viajeros al Nuevo Mundo que permiten reconstruir el complejo entramado de lecturas y la circulación de textos e ideas propios del período en cuestión.

6 En principio, resulta necesario comprender que el enfrentamiento entre De Pauw y Pernety, o lo que el historiador italiano Antonello Gerbi (1982) refirió en 1955 como la "disputa del Nuevo Mundo", fue ante todo una batalla de fuentes (Duchet 1975, p. 90). En efecto, hacia la segunda mitad del siglo XVIII, al tiempo que el estatus y la naturaleza de América fueron objeto de severo escrutinio, los criterios de credibilidad sobre los que podía sustentarse la veracidad de las fuentes también fueron reevaluados en función de nuevas técnicas historiográficas. Dichos cuestionamientos se habían originado en realidad en el siglo XVII cuando, en los debates académicos más generales sobre la existencia o no de milagros, la crítica "externa" de los testimonios terminó siendo sustituida por la crítica "interna”. En términos de Jorge Cañizares Esguerra (2007), las fuentes comenzaron a ser juzgadas entonces "por su consistencia interna, y no por la posición social o la educación de los testigos" (p. 20), lo que llevó en consecuencia al fin del buen crédito del que había gozado hasta aquel momento el testimonio del testigo presencial.

7 Una de las consecuencias más notorias de este fenómeno fue la pérdida de credibilidad de los primeros relatos españoles, cuyo testimonio fue en gran medida abandonado frente a la autoridad que comenzaron a detentar las relaciones más recientes, producto de las expediciones de reconocimiento de las costas e interior americano lideradas por Francia e Inglaterra. Tal como ha señalado Michèle Duchet (1975), "estas últimas se [beneficiaron] de un prejuicio favorable, en la medida en que se [consideró] a priori a sus autores como personas más ilustradas e instruidas que sus predecesores" (p. 94). Por su parte, en la opinión de los filósofos ilustrados, las crónicas españolas producidas en los primeros tres siglos de ocupación ibérica en América resultaban ahora poco confiables dada la naturaleza de los testigos; aspecto que a su vez se hallaba en estrecho vínculo con el interés político de las potencias rivales de España por denostarla (Pimentel 2000, p. 28). El rechazo a este tipo de fuentes se vio acompañado a su vez por un nuevo "arte de la lectura" en el que no se privilegiaba ya a los testigos presenciales (Cañizares Esguerra 2007, p. 38) y, en el caso de que se contemplara su testimonio como evidencia, eran sopesadas la nacionalidad y la competencia o imparcialidad del viajero (Duchet 1975, p. 98, Pimentel 2003b, p. 242).

8 Fue en este contexto que se potenció una visión denigratoria de la naturaleza de América, la cual llevó por su parte a una revisión de las descripciones humanistas sobre las sociedades americanas que hasta entonces se habían centrado en resaltar las bondades del hombre natural y las costumbres de las poblaciones no europeas (Cañizares Esguerra 2007, p. 22). Las historias "filosóficas", tales como la Histoire des deux Indes (1770) del Abate Raynal así como la Histoire Naturelle (1749-1788) del Conde de Buffon o las Recherches philosophiques sur l'Amérique et les Américains (1768-1769) de De Pauw aparecen en este 
período como claros intentos de construir una imagen de América que se alejara de aquella mirada renacentista.

9 En efecto, a través de recursos y pruebas provenientes de la lingüística, la historia natural, la etología y la geología, De Pauw puso en duda la credibilidad de los testimonios hasta entonces publicados sobre América (Cañizares Esguerra 2007, p. 27). Su objetivo no era otro que asignar a este continente un lugar que, para este filósofo, no debía ser más que secundario (cuando no subordinado) dentro de la gran historia y desarrollo del mundo. Más allá de sus conclusiones, en términos metodológicos la propuesta resultó ciertamente innovadora. Esto se debió principalmente a que la interpretación de América presentada por De Pauw se sustentaba en una serie de relatos de viaje pero a la vez, sostenía el holandés, se encontraba depurada de todos sus males, presentando de este modo una forma renovada de leer la historia del Nuevo Mundo (Cañizares Esguerra 2007, p. 59).

10 En el caso de Pernety, es muy probable que haya sido justamente su experiencia en América como capellán de barco del primer viaje francés a las islas Malvinas la que despertara, a su regreso, la necesidad de confrontar las negativas reflexiones de Cornelius de Pauw sobre la naturaleza americana. En efecto, entre 1763 y 1764 Pernety había sido parte de la primera expedición francesa a las islas Malvinas que, liderada por LouisAntoine de Bougainville, se convertiría en la antesala del primer viaje francés de circunnavegación emprendido dos años después por el mismo Bougainville, aunque ya no en compañía de Pernety. ${ }^{5}$ Producto de su experiencia en América, en 1769 Pernety había publicado en Berlín un Journal historique d'un voyage fait aux îles Malouines, que al año siguiente sería adaptado al público general y editado bajo el ya mencionado título de Histoire d'un voyage aux Îles Malouines (1770).

11 Ese mismo año Pernety también daría a conocer su Dissertation sur l'Amérique et les Américains... En ella, el benedictino apelaba a su propia experiencia así como a la de viajeros contemporáneos tales como Amédée Frézier, el padre Feuillée, Antonio de Ulloa y Charles-Marie de La Condamine para ofrecer a De Pauw un conjunto de testimonios respetados que diera por tierra con las hipótesis defendidas por este último acerca de la degeneración de América, publicadas en sus Recherches philosophiques sur les Américains, ou Mémoires intéressants pour servir à l'histoire de l'espèce humaine de 1768. A las claras, Pernety está al tanto del descrédito en el que han caído las fuentes españolas del primer siglo de conquista y es por ello que presenta a su adversario testimonios novedosos y experiencias de viaje recientes y, a su criterio, confiables. Esto no implica, sin embargo, que el autor no reconozca, por otra parte, el valor de algunos de los primeros testimonios existentes sobre la vida en América: como podrá observarse más adelante a partir de otras apreciaciones vinculadas a su defensa de la naturaleza americana, Pernety pareciera ubicarse a caballo respecto de los criterios historiográficos adoptados por sus contemporáneos y una valoración de las fuentes propia del Renacimiento.

De Pauw, por su parte, no tardó en reaccionar antes las invectivas de Pernety. Pocos meses después de que este último publicara su Dissertation..., el abate holandés lanzaría su Défense des Recherches philosophiques sur les Américains (1770b), que al año siguiente sería cuestionada por Pernety en su Examen des "Recherches philosophiques sur l'Amérique et les Américains et de la "Défense" de cet ouvrage (1771).

13 Ahora bien, toda aproximación al debate entre De Pauw y Pernety sobre la naturaleza americana tampoco debería soslayar el hecho de que en el siglo XVIII, a partir de nuevas herramientas conceptuales y experiencias de viaje concretas, lo verdaderamente 
discutido fue no solo el lugar de América en la historia natural, sino su participación pasada y futura en el mundo político, económico y social. En este sentido, es necesario reconocer que el debate sobre la naturaleza de América no buscó solamente definir cuál había sido el lugar de esta región en la historia del mundo, sino también cuál sería su papel y el de su contraparte, Europa, en un futuro cercano (Gerbi 1982, p. 196). En efecto, aunque solapadamente, las reflexiones de Pernety y De Pauw dejan entrever los conflictos entre potencias ultramarinas en ese "nuevo descubrimiento de América" (Pimentel 2003b, p. 237) ${ }^{6}$ que se inicia a fines del siglo XVII y principios del XVIII y que "representó no solo un cambio decisivo en la configuración regional y productiva de las colonias españolas, sino también (...) su reinstalación en el interés de los Estados europeos..." (Paredes 2011, p. 103). Por su parte, las expediciones científicas realizadas por Francia, de las que sabemos a través de los relatos de Feuillée, Frézier, La Condamine y también Pernety, ilustran claramente cómo la búsqueda de conocimiento y el afán por medir el mundo e incorporar nuevos saberes no las privó, sin embargo, de su carácter geopolítico.

De igual forma, el descrédito en el que cayeron las crónicas y relatos españoles en esta época bien podría entenderse como corolario del ataque protestante a la conquista y colonización española de América que, iniciado con la llamada Leyenda Negra en el siglo XVI, persistió hasta avanzado el siglo XVIII (Cañizares Esguerra 2007, p. 23). ${ }^{7}$ Tal como ha señalado Antonello Gerbi (1982), las implicancias políticas del debate sobre la naturaleza de América no deberían ser en este sentido desestimadas (p. 3), por lo que toda lectura de la obra seleccionada deberá necesariamente hacerse eco del conjunto de variables contextuales hasta aquí señaladas. A fin de cuentas, tanto la postura de De Pauw como la de Pernety reflejan no solamente una disputa de tipo heurístico respecto de la validez o no de los relatos y fuentes provenientes de América, sino también una serie de variables geopolíticas en las que, poniendo en duda el conocimiento científico que España podía tener sobre sus propios dominios, Francia e Inglaterra renovaron su interés por América.

\section{Algunas precisiones sobre el fragmento seleccionado y el acceso a la fuente en distintos repositorios locales}

El texto que a continuación se presenta corresponde al prefacio y a la primera parte de la Dissertation sur l'Amérique et les Américains, contre les Recherches Philosophiques de M. de P***8, cuyo título es Disertación sobre América y los naturales de aquella parte del mundo y que, hasta el presente, no ha sido traducido al castellano. Respecto de la copia utilizada para la presente traducción, esta corresponde a la primera edición de la obra, publicada en Berlín en 1770, y forma parte del acervo documental de la Biblioteca del Museo Etnográfico "Juan B. Ambrosetti" de la Facultad de Filosofía y Letras de la Universidad de Buenos Aires. También puede accederse a una versión digitalizada de la misma en el portal web de la Biblioteca Nacional de Francia, entre otros repositorios digitales. ${ }^{9}$

Tal como ha sido mencionado en el apartado precedente, la Dissertation, publicada por Pernety en 1770, debe entenderse entonces como su respuesta a las Recherches philosophiques sur les Américains de Cornelius De Pauw, publicadas por primera vez en Berlín entre 1768-1769. Aunque debe señalarse que la primera refutación que el benedictino hizo de la obra de De Pauw fue en realidad la que leyó en 1769 ante la Academia de Berlín y sobre la que hace alusión en la traducción que aquí se presenta 
(Pernety 1770b, p. 5). Cuando en el mismo año de 1770 De Pauw publicó su Défense des Recherches philosophiques sur les Américains, su propósito fue claramente el de refutar los argumentos de Pernety para continuar así reivindicando, aunque con algunas concesiones, sus tesis antiamericanistas y la degeneración del continente y todo su contenido (Gerbi 1982, pp. 116-118, Zantrop 1997, p. 47). ${ }^{10}$

En Examen des "Recherches philosophiques sur l'Amérique et les Américains » et la "Défense » de cet ouvrage (1771), la última publicación producto de la disputa entre ambos autores, Pernety no agregó, sin embargo, nuevos argumentos contra las tesis de De Pauw. Antes bien, el benedictino pareció aferrarse aún más a los argumentos esbozados en su Dissertation, proveyendo para ello ejemplos todavía más detallados y extensos que los utilizados previamente.

Ciertamente, la publicación de las cuatro obras mencionadas en un intervalo de dos años da cuenta no solamente de que se había arribado al punto más álgido en la controversia sobre la naturaleza del Nuevo Mundo, sino del éxito comercial que este tipo de debate podía representar en el mercado editorial. En efecto, el papel de la prensa periódica, y en especial de las publicaciones científicas, no debe ser desestimado en la difusión del debate y la búsqueda de consenso frente a la opinión pública. Tal como han señalado Patrice Bret y Jean-Luc Chappey (2012, p. 4), la segunda mitad del siglo XVIII se caracteriza por el dinamismo de las publicaciones científicas, cuyo número crece de manera inusitada. La consecuencia más inmediata de este fenómeno fue la densificación y aceleración de los intercambios entre científicos, por un lado, y la ampliación del público lector, por el otro, factores que a su vez empujaron a los empresarios del mundo libresco a invertir cada vez más en este tipo de material de divulgación. ${ }^{11}$

No es casual entonces que al comienzo de su Dissertation... Pernety mencione haber tenido por intención primera la inserción de sus observaciones y notas sobre la obra de De Pauw en una gaceta literaria (Pernety 1770b, pp. 4-5) o que, tal vez en la búsqueda de reconocimiento social o consenso, a lo largo de la primera parte prevenga al "público" y a los "lectores" sobre los posibles errores en los que ha incurrido De Pauw. Asimismo, el hecho de que el benedictino haya leído la primera parte de su disertación ante la Academia de Berlín y que esta haya aprobado su refutación de los postulados de De Pauw también da cuenta del peso que este tipo de instituciones podía tener en la promoción y la circulación de obras de este tipo o en la defensa de una posición estratégica en una querella filosófica.

En cuanto al acceso y disponibilidad en la ciudad de Buenos Aires de las publicaciones que dieron cuenta del debate entre estas dos figuras, debe señalarse que, además del mencionado original de 1770 con el que cuenta la Biblioteca del Museo Etnográfico "Juan B. Ambrosetti", en este repositorio también puede hallarse una edición conjunta, publicada en Londres en 1774, de las primeras dos obras de estos autores, ${ }^{12}$ así como una copia de la primera edición de la Histoire d'un voyage aux Isles Malouines, fait en 1763 \& 1764; avec des observations sur le Detroit de Magellan, et sur les patagons, publicada en dos volúmenes en París en $1770 .{ }^{13}$ La edición original de este viaje también puede hallarse en la Sala "Dr. Juan Ángel Fariní" del Tesoro de la Biblioteca Pública de la Universidad Nacional de La Plata y en la Sala del Tesoro de la Biblioteca Nacional de Maestros. A su vez, en la mencionada Sala "Dr. Juan Ángel Fariní" también se encuentran dos copias de la Défense des recherches philosophiques sur les Americaines de Cornelius De Pauw, publicadas en Berlín en 1770 y 1772 y una copia del ya mencionado compendio De Pauw-Pernety publicado en Londres, aunque en este caso, en 1771. Este último compendio también 
puede hallarse en la Sala del Tesoro de la Biblioteca Nacional de Maestros en la ciudad de Buenos Aires.

\section{Mecanismos de argumentación y uso de referencias en la Disertación sobre América y los americanos de Antoine-Joseph Pernety: una aproximación analítica}

\section{de Antoine-Joseph Pernety se encuentra dividida en dos partes, además de contar con un} muy breve prefacio. La primera de estas, cuya traducción al castellano se presenta aquí por primera vez, lleva como título "Disertación sobre América y los naturales de aquella parte del mundo" y es la que será analizada en detalle a continuación. En cuanto a la segunda parte, la misma se encuentra dividida a su vez en tres secciones. Una primera, "sobre el suelo de América". Una segunda, que reflexiona "sobre las cualidades físicas de los americanos" y una tercera acerca de "las cualidades del corazón y del espíritu" de los mismos. En lo que refiere específicamente al formato de la obra, desde su editio princeps la misma fue siempre publicada in-octav $0^{14} \mathrm{y}$ contó con un total de aproximadamente 116 páginas, variable según la edición.

como se adelantó en el apartado introductorio, el objetivo principal de la misma fue e de presentar una serie de argumentos y pruebas que pusieran en evidencia el desacertado juicio de Cornelius De Pauw sobre la naturaleza de América, producto de lo que el benedictino considera su desinformación sobre el Nuevo Mundo. Para ello, Pernety retoma algunos de los argumentos presentados por De Pauw en la publicación que diera origen al debate, ${ }^{15}$ los analiza en detalle y propone lo contrario a través de una serie de ejemplos. El mecanismo se repite a lo largo de la obra de forma tal que hacia el final de la misma, cada uno de los argumentos contra la naturaleza de América expresados por De Pauw en sus Recherches Philosophiques... es refutado exhaustivamente por Pernety. ${ }^{16}$ análisis en dos partes puesto que la riqueza del texto reside, por un lado, en los mecanismos de argumentación empleados por el autor y por el otro, en el abanico de alusiones y referencias que este emplea para refutar los postulados antiamericanistas de De Pauw. Debido a que muchas referencias son utilizadas por Pernety para enriquecer su propia argumentación y por ello presentadas como "evidencia" o fundamento de sus declaraciones, serán analizados en primer lugar sus argumentos y luego detalladas las referencias concretas a los viajeros, relatos y memorias escogidos por el autor para reforzar sus ideas.

En lo que refiere entonces a los argumentos empleados por Pernety para rebatir las tesis de De Pauw, el más contundente es sin duda la primacía que el benedictino otorga al testimonio directo. A diferencia de De Pauw y de la tendencia generalizada en el siglo XVIII de juzgar la validez de un relato en función de su análisis interno y no así de las aptitudes o cualidades del testigo presencial, Pernety se escuda en la tradición renacentista y privilegia los informes de los viajeros a América por sobre las descripciones de aquellos que no han viajado y, en consecuencia, desconocen el continente que sin embargo critican.

Esta primera estrategia argumentativa puede observarse desde el comienzo de la sección traducida, cuando De Pauw es acusado de hablar sobre aquello que no conoce y, en 
consecuencia, de presentar una imagen "travestida" del nuevo continente. Desde el Prefacio, entonces, Pernety contrapone el valor del testimonio a las inferencias e hipótesis "de gabinete" realizadas por De Pauw, haciendo especial énfasis en la falta de conocimiento "real" que el filósofo holandés tiene de América y en la validez de su propio testimonio por haber viajado a aquellas tierras. ${ }^{17}$ "Reconocí que M. de P. o sabe poco de América y de lo que ella contiene o que, para apoyar la opinión de un autor que había adoptado (...) se había puesto como deber criticar todo acerca del Nuevo Mundo y sus producciones", expresa Pernety, para poco después ofrecer como garantía de sus propios postulados el hecho de que él mismo ha viajado a las tierras que describe: "he visto con mis propios ojos la mayoría de las cosas que son relatadas" (Pernety 1770b, p. 4). Algunas páginas más adelante volverá a señalar el error que De Pauw ha cometido al hablar con autoridad acerca de algo que en realidad jamás ha visto: "Si M. de P. hubiese viajado a América y la hubiese recorrido en persona, la hubiera conceptuado y observado verdaderamente con otros ojos" (Pernety 1770b, p. 12).

La importancia de "lo vivido" o de "lo observado" es resaltada nuevamente cuando Pernety invoca las memorias de Charles-Marie de La Condamine, acaso el viajero filosófico por excelencia cuyo testimonio es utilizado en las obras de De Pauw y Pernety con fines ciertamente diversos. Para Pernety, entonces, el testimonio de La Condamine resulta una fuente válida debido a que habla a partir de lo que ha visto con sus propios ojos (Pernety 1770b, p. 17). El lugar del testigo ocular y del testimonio que este genera a partir de su experiencia deviene, de esta forma, uno de los instrumentos más eficaces para refutar los postulados de De Pauw. Tal como ha señalado Juan Pimentel, a diferencia de los viajeros de siglos anteriores, interesados en dar cuenta de la maravilla o de lo insólito, desde mediados del siglo XVIII el afán por "la testificación neutra, detallada y minuciosa de las realidades naturales" (Pimentel 2003a, p. 63) se había convertido en una de las características más sobresalientes de los viajeros ilustrados.

Por su parte, en tanto viajero al Nuevo Mundo, la producción escrita de Pernety también pareciera hacerse eco de aquella retórica de la verdad y del afán por la testificación objetiva e imparcial de los hechos con los que el historiador español ha caracterizado al viajero ilustrado (Pimentel 2003a, p. 64). ${ }^{18}$ En efecto, en el transcurso de la expedición francesa realizada a las islas Malvinas entre 1763 y 1764, Pernety no solo había oficiado de capellán sino que también, en calidad de testigo directo, había registrado todo aquello que llamó su atención de la flora y fauna americanas. En 1770 sus observaciones y experiencias de viaje fueron publicadas bajo el título de Historia de un viaje a las Islas Malvinas ${ }^{19}$, relato donde Pernety se esforzaba en presentar una mirada renovada del suelo americano pero donde además podía ya percibirse la postura del benedictino frente a la naturaleza americana. Es en este texto, por ejemplo, donde el capellán destaca por primera vez las cualidades físicas de los indios del Paraguay, a quienes describe como "bien hechos" y cuyo cuerpo "estaba erguido, las piernas y brazos contorneados, el pecho amplio y los músculos del cuerpo bien delineados" (Pernety 1770a, p. 299). También para Pernety son más feroces los animales salvajes de América que aquellos de África y de las Indias Orientales (Martínez 2011, p. 195). ${ }^{20}$

En lo que refiere específicamente al contenido de su Dissertation, el valor del testimonio es resaltado nuevamente cuando, algunas páginas más adelante, Pernety enumera las tres condiciones de las que debe gozar una relación antigua para resultar confiable. ${ }^{21} \mathrm{Al}$ respecto, el benedictino señala que este tipo de fuentes es fiable siempre y cuando el testigo cumpla con la siguiente serie de condiciones: 
Hay que atenerse a las relaciones antiguas y darles preferencia sobre las nuevas cuando tienen las tres condiciones requeridas para una buena historia: que hayan sido compuestas por autores desinteresados en sus relatos; que esos autores no hayan querido burlarse de la verdad; y que a una buena memoria sumen bastante inteligencia y espíritu para contar aquello que han visto (Pernety 1770b, p. 15). considerársela confiable según Pernety se basan principalmente en el lugar ocupado por el autor y en su integridad al momento de relatar aquello que nadie más ha visto. En este punto, los exigencias de Pernety se asemejan a aquellas de Michel de Montaigne, quien en su ensayo Sobre los Canibales (1580) parecía haber establecido que las tres condiciones que todo testimonio debía tener para gozar de autoridad eran la razón, la información y la fidelidad (De Certeau 2007, p. 274). Tal como fue señalado en el apartado introductorio, dichos requerimientos, tenidos en gran estima en el siglo XVI, habían dejado de constituir, sin embargo, la norma en el siglo XVIII. En efecto, en 1770 Pernety construye su argumentación sobre un criterio de verdad que no es ya el compartido por sus contemporáneos y del que difieren tanto De Pauw como otros estudiosos de América. Ahora bien, esto no significa que Pernety no haya compartido junto a sus contemporáneos la creencia en el carácter dudoso y aún falaz de algunas crónicas y relatos españoles, producidos en las primeras décadas del descubrimiento. ${ }^{22}$ Efectivamente, al igual que De Pauw, Pernety admite la inclinación de algunos viajeros a la exageración y a la fantasía, puesto que a ellos, señala el autor, "las extravagancias cuestan menos que al resto de los hombres" (Pernety 1770b, p. 8).

En lo que refiere específicamente a los primeros cronistas españoles, el benedictino acuerda nuevamente con De Pauw (Pernety 1770b, pp. 15-16) y acepta "aquello que él dice de los historiadores españoles sobre el tema de Perú; lamentablemente, todo ese retrato, cuando se lo examina con atención, no es más que una ficción, una sarta de mentiras y de exageraciones" (Pernety 1770b, p. 15). Ciertamente, Pernety no reniega del descrédito en el que han caído las crónicas y relatos españoles, y en consecuencia propone nuevas figuras de autoridad que reemplacen, con sus relatos, las "relaciones de los antiguos autores españoles" (Pernety 1770b, p. 20). ${ }^{23}$ Los testimonios que el benedictino utiliza para refutar las críticas de De Pauw no son entonces las devaluadas crónicas españolas del siglo XVI, sino los relatos de viajeros contemporáneos de nacionalidad francesa e inglesa tales como los del padre Feuillée, Amédée Frézier, La Condamine y el, un tanto oscuro, inglés Bristock. ${ }^{24}$

En este sentido, merece una mención aparte su alusión al español Antonio de Ulloa, que en la fuente analizada es presentada como el ejemplo de un relato fidedigno escrito por un español en el siglo XVIII a partir de los instrumentos y de las experimentaciones llevadas a cabo por una expedición hispano-francesa. Se trata de aquella liderada por Charles-Marie de La Condamine entre 1735 y 1746 y que tuvo por objetivo medir el arco de un meridiano terrestre en el Ecuador. Tal como ha señalado Michèle Duchet, "Jorge Juan y Ulloa fueron dos matemáticos españoles a quienes su gobierno encargó de ayudar -de hecho, de vigilar- a los sabios franceses que acompañaron a La Condamine en su viaje al Perú. Los dos voluminosos in-quarto de su Voyage ofrecen un cuadro completo de los establecimientos españoles en el Perú y en la Nueva Granada" (Duchet 1975, p. 100). Por su parte, Neil Safier ha señalado la importancia que tuvo la participación de Jorge Juan y Antonio de Ulloa en la expedición francesa en la voluntad de la Corona española, ahora bajo control del monarca Borbón Felipe V, por 'demostrar la naturaleza 'ilustrada' de la nueva monarquía ibérica y aumentar el prestigio de España” (Safier 2008, p. 7). Lejos 
del descrédito en el que habían caído los primeros cronistas españoles, el testimonio de Ulloa goza entonces de validez en tanto producto de una experiencia de viaje contemporánea y bajo el signo de la nueva ciencia ilustrada.

La segunda estrategia argumentativa utilizada por Pernety para rebatir los postulados de De Pauw sobre América es la comparación. En efecto, en el transcurso de su Dissertation Pernety compara los males de Europa y América para invalidar la aserción de De Pauw respecto de lo beneficiado que se encontraba el continente europeo respecto del americano (Pernety 1770b, p. 13). En las páginas 13 y 14 del apartado traducido, pero también a lo largo de la obra, mediante múltiples ejemplos el benedictino hace especial hincapié en las desventajas de Europa respecto de su clima, la fertilidad del suelo, las características de la tierra y las duras tareas que deben realizar sus campesinos para sacar algún provecho de ella. Es "a estos últimos a quienes hay que consultar: a ellos corresponde comparar el estado del suelo en América y de sus habitantes con el estado y el valor de nuestro Continente", señala Pernety para poner en evidencia la distancia que separa a aquellos dedicados a realizar apreciaciones filosóficas diversas, tales como De Pauw, de los verdaderos testigos del trabajo que implica labrar una tierra no siempre fértil (Pernety 1770b, p. 14).

América, por el contrario, es presentada como una tierra de abundancia, de clima benigno y rica en recursos naturales. Para Pernety prueba irrefutable de ello es el hecho de que desde el siglo XVI "los europeos han estado extrayendo de ella increíbles riquezas y continúan estableciéndose en América para abastecerse de lo que esta tierra produce y no se encuentra en tanta abundancia en Europa" (Pernety 1770b, p. 214). A pesar de que este último punto no es mencionado en la primera parte de su Dissertation, constituye sin duda una de las argumentaciones más fuertes utilizadas por el benedictino contra los embates de De Pauw:

Más reflexiono sobre la idea que M. de P. se esforzó en darnos de América, menos la encuentro en conformidad con aquella que nosotros tenemos. Esta parte del Globo es, desde su descubrimiento, el gran, poderoso y rico amante de los europeos. Europa, la parte más pequeña de la tierra en la repartija que plugo a los hombres hacer, aspiró desde aquel tiempo a compensar su poca extensión, y aquello que le falta, buscando arduamente los bienes que la Naturaleza le negó, y los cuales, esta madre en común que no ama igualmente a sus hijos, prodigó a ciertos países.

En efecto, si los europeos pensaran como M. de P., ¿se vería esa competencia tan fuerte, tan afanosa de ir a establecerse en América y buscar allí todas sus producciones? La fatiga, los peligros, las incomodidades, nada nos desanima. Aunque la avaricia y la codicia hayan hecho recorrer Asia y África, no es nada en comparación con América. Desde que se conoce ese vasto continente, con qué afán no se procuró sacar partido de esos restos? Puede decirse sin exageración, que de allí vinieron riquezas inmensas de todo tipo. (Pernety 1770b, p. 114)

Respecto del ejercicio de comparación propuesto por Pernety, debe señalarse que este también involucra a los habitantes de uno y otro continente. En efecto, tras haber comparado los puntos fuertes y débiles de ambas regiones, retomando las observaciones de Charles-Marie de la Condamine, el autor destaca las habilidades de ciertas culturas originarias, capaces de producir "cosas tan bellas como la industria y la habilidad de nuestros mejores obreros" (Pernety 1770b, p. 18). De igual forma, demuestra que los americanos no son perezosos, tal como los acusa De Pauw, sino que no realizan actividades que les generan fatiga por haber sido la naturaleza tan generosa con ellos (Martínez 2011, p. 201). 

topos del "buen salvaje", que los grandes viajes de descubrimiento de fines del siglo XV inauguran, pero que se resignifica en el siglo XVIII en función de los debates planteados en torno al lugar de Europa frente al mundo (Lestringant 1993, 1994). En el caso de Pernety, la figura del "buen salvaje" es retomada al momento de defender las bondades de América y, en especial, de sus habitantes. En efecto, a lo largo de su disertación el benedictino se refiere con frecuencia a la hospitalidad y buena predisposición de los indígenas americanos hacia los viajeros europeos (Pernety 1770b, p. 23). En esta línea, Pernety llega incluso al punto de preguntarse, así como lo habían hecho el pastor hugonote Jean de Léry y el ya mencionado Montaigne en el siglo XVI, quién, entre los americanos y europeos, "merece a más justo título el nombre de salvaje" (Pernety 1770b, p. 111). Las semejanzas con Léry no se detienen, sin embargo, allí. Al igual que este último había hecho en su Historia de un viaje hecho a la tierra de Brasil (1578), ${ }^{26}$ Pernety también compara los grados de hospitalidad expresados por americanos y europeos para terminar pronunciándose en contra de "la máscara muy imperfecta de la verdadera hospitalidad" con la que se cubren los europeos (Pernety 1770b, p. 23). Codicciones diversas tales como la del hugonote Jean de Léry en el siglo XVI y las de benedictino Pernety en el siglo XVIII. Antes bien, el objetivo aquí es mostrar cómo ciertos recursos y topos propios del siglo XVI podían ser aún retomados en el siglo XVIII para enfrentarse al auge de la crítica interna de los documentos, que para Jorge Cañizares Esguerra se generaliza en este período (Cañizares Esguerra 2007, p. 38).

analizado los mecanismos de argumentación empleados por el autor, en función de estudiar los diversos personajes y lecturas a los que alude el autor conviene adentrarnos ahora en la serie de referencias a autores, poblaciones, lugares y textos presentes en el fragmento de la fuente seleccionada. En primer lugar, debe señalarse que el principal destinatario de la obra de Pernety, aquel M. de P.***, no es otro que el ya 
mencionado Cornelius De Pauw. Aunque lejos de ser un simple destinatario, De Pauw merece en realidad el título de interlocutor. Tal como fue señalado al comienzo del presente trabajo, la disputa sobre la naturaleza de América iniciada por ambos autores en 1769 se prolongó hasta 1771 y en total comportó cuatro publicaciones en las que los mismos retomaban los postulados de su oponente para refutarlos nuevamente. Hemos visto cómo en el caso particular de la Dissertation, Pernety se propuso responder específicamente a la invectivas lanzadas por De Pauw en sus Recherches philosophiques sur l'Amérique et les américaines, la primera obra publicada por este último autor y en la que quedaron plasmados sus principales argumentos a favor de la degeneración americana.

Ahora bien, además de estar dirigida contra De Pauw, la obra de Pernety también pareciera posicionarse contra las hipótesis sobre América desarrolladas por GeorgesLouis Leclerc, conde de Buffon, y retomadas luego por el filósofo holandés. En efecto, en el Prefacio, Pernety alude indirectamente a este último cuando acusa a De Pauw de criticar el Nuevo Mundo y sus producciones en su ambición de "apoyar la opinión de un autor que había adoptado" (Pernety 1770b, p. 4; Gerbi 1982, p. 209). Aunque soslayada, la referencia a Buffon se vincula con el hecho de que el modelo propuesto por De Pauw para criticar la historia natural americana se había basado en gran medida en los postulados ya esbozados por el naturalista francés (Cañizares Esguerra 2007, p. 92). En efecto, Michèle Duchet ha atribuido al propio Buffon la mirada condenatoria del hombre americano que otros historiadores vincularon exclusivamente a De Pauw (Duchet 1975, p. 29).

41 En la opinión de Antonello Gerbi, por el contrario, de todas las hipótesis esbozadas por Buffon en su Historia Natural, general y particular (1749-1778), en detrimento del naturalista, fueron sus postulados más objetables los que terminaron por alimentar la disputa en torno a la naturaleza del Nuevo Mundo. En este sentido, más allá de que Gerbi adjudique a Buffon el nacimiento de la tesis sobre la "debilidad" o "inmadurez" del continente americano, para el historiador italiano la radicalidad y difusión con la que se denigra la naturaleza de América fue responsabilidad casi exclusiva de Cornelius De Pauw (Gerbi 1982, p. 67). De tal forma, si bien a lo largo de Recherches philosophiques... De Pauw retoma las hipótesis de Buffon sobre el Nuevo Mundo, también se encarga de exacerbar las características negativas que el naturalista francés había asignado a la flora y fauna americanas pero no necesariamente a sus habitantes. ${ }^{27} \mathrm{Al}$ parecer de Gerbi entonces, más allá de que Buffon se hubiese esforzado particularmente en dejar al hombre americano fuera de su tesis sobre la degeneración de América (De Pauw 1768, p. 307), las hipótesis del naturalista francés fueron las que mejor se adaptaron a los postulados antiamericanistas del abate holandés.

En cuanto al uso de referencias y citas que Pernety hace para apoyar sus argumentaciones, es posible observar que, en su afán de presentar a De Pauw argumentos articulados en base a relatos recientes y no a las estigmatizadas primeras crónicas españolas, en la primera parte de la obra el benedictino retoma las reflexiones del padre Feuillé, de Amédée Frézier, de Charles-Marie de La Condamine, de Antonio de Ulloa y de Charles Rochefort, quien menciona a su vez los descubrimientos realizados por un inglés de apellido Bristock al norte de la península de Florida.

En el caso del padre Feuillé (Pernety 1770b, pp. 18, 26), tanto su nombre como el de Frézier aparecen vinculados al debate en torno al grado de desarrollo alcanzado por los Incas, tema que fue discutido vivamente en este período. En efecto, a lo largo del siglo XVIII la controversia en torno a la grandeza de la civilización inca fue un tema de discusión corriente donde la profusión de testimonios muchas veces contradictorios no 
solo animaba el debate sino que en muchas ocasiones pareció volverlo aún más confuso (Duchet 1975, p. 42). Lejos de compartir esta perspectiva, en la opinión de Pernety los testimonios de ambos viajeros debían aceptarse como prueba suficiente del grado de desarrollo alcanzado por las poblaciones andinas antes de la llegada de los españoles a aquellas regiones.

En realidad, ambos habían viajado por América a principios del siglo XVIII como parte de la tripulación de dos expediciones organizadas por la Corona francesa, que con aparentes fines científicos también se habían propuesto espiar los dominios españoles y sus quehaceres en las costas del Pacífico. ${ }^{28}$ En efecto, al igual que lo había sido Feuillé en 1707, en 1712 Frézier fue enviado a reconocer las costas occidentales de América como parte de un programa de cooperación militar entre Francia y España. El verdadero objetivo del viaje, no obstante, no había sido otro que el de reunir información para un eventual ataque a los puertos de Chile y Perú (Pernety 2012, p. 18).

Los objetivos geopolíticos de ambos viajeros no parecen, sin embargo, revestir demasiada importancia para Pernety, para quien el hallazgo de acueductos y viejas fortificaciones había convertido a los expedicionarios franceses en excelentes testigos de aquella América que, aun con recursos diferentes, había llegado a desarrollar técnicas tan precisas y eficientes como las de Europa. Con el objetivo de demostrar el grado de desarrollo alcanzado por los habitantes del Perú prehispánico así como por algunos pueblos de la costa occidental de América del Sur, Pernety recurre entonces a los informes del padre Louis Feuillée ${ }^{29}$ y al relato de viaje de Amédée Frézier. ${ }^{30}$ En este sentido, tanto los acueductos y como las construcciones de adobe hallados en las costas de Chile y Perú descriptos por el segundo como las apreciaciones de Feuillée sobre el pasado inca son utilizados por el benedictino para construir una imagen laudatoria de América y sus habitantes.

Este tipo de testimonio, reciente pero a la vez utilizado para justificar un pasado remoto, será no obstante impugnado por De Pauw. En efecto, en su Défense des Recherches Philosophiques sur les Américains de 1770, al analizar "el estado de las artes entre los peruanos, en tiempos del descubrimiento de su país" (capítulo XXVIII), De Pauw hace especial hincapié en la importancia que reviste la posición del observador frente a los hechos narrados. La impugnación al testimonio de Feuillée en favor del testimonio del español Zárate, propio del siglo XVI, es en este sentido clara, aunque un tanto contradictoria si se toma en cuenta el desdén del filósofo holandés por las fuentes españolas producto de las primeras décadas de ocupación en América. A pesar de esta aparente contradicción, De Pauw rechaza con firmeza el relato de Feuillée: "hay que preferir un autor contemporáneo que, por su profesión, estaba en la obligación de conocer todas las poblaciones de Perú, ya que debía fijar el tributo, a un viajero tal como el Padre Feuillée, venido casi doscientos años depués que Zárate" (De Pauw 1770b, p. 148).

En lo que refiere al testimonio de Charles-Marie de La Condamine (Pernety 1770b, p. 16-18), resulta de interés señalar que, tal como fue indicado al comienzo de este apartado, sus observaciones sobre América son utilizadas tanto por De Pauw como por Perenty para fundamentar sus argumentos. En efecto, De Pauw es el primero en citar las opiniones de La Condamine, a quien considera "uno de los pocos testigos confiables que había penetrado en el imperio hispanoamericano" (Cañizares Esguerra 2007, p. 62). Pernety, por su parte, acusará a De Pauw de haber realizado una selección arbitraria de los dichos de La Condamine, omitiendo los postulados que podrían haberle hecho alguna justicia a América. En términos del propio Pernety, más allá de haberse referido a La Condamine, 
De Pauw "se abstuvo de reproducir el texto, demasiado opuesto al proyecto concebido por éste, de criticar a América y a sus habitantes" (Pernety 1770b, p. 17). Frente a ello, el benedictino citará la Mémoire sur anciens monumens, que el viajero-filósofo había presentado en 1746 ante la Academia de Ciencias de Berlín y en donde comparaba las descripciones de los palacios incas realizadas por Garcilaso con sus propias observaciones. Ahora bien, más allá de aquello que pudiera haber expresado La Condamine en su Mémoire , lo cierto es que el viajero-filósofo es el autor predilecto de De Pauw, quien al comienzo de su última obra en el gran debate sobre la naturaleza de América invitará al lector a creer siempre en él, que ha pasado seis años en América, antes que en Pernety, quien sólo ha permanecido escasos meses en ella. ${ }^{31}$ Esto no significa, sin embargo, que La Condamine haya compartido las tesis antiamericanistas del filósofo holandés. Antes bien, en muchos sentidos sus perspectivas sobre América se asemejan más a aquellas de Pernety que a las de De Pauw. En efecto, en la opinión de Antonello Gerbi, lejos de referirse a los "nefastos influjos del ambiente físico" La Condamine sólo habla con entusiasmo de la naturaleza americana (Gerbi 1982, p. 133).

El hecho de que el viajero francés haya sido citado por ambos autores no debe, entonces, resultar extraño. ${ }^{32} \mathrm{Tal}$ como ha señalado Michèle Duchet, una vez publicadas, las relaciones de La Condamine podían hallarse en todas las bibliotecas y pronto se convirtieron en la fuente más aceptada de todo lo que podía decirse o escribirse sobre el Perú, los salvajes del Amazonas y también Guayana. Es por ello que, así como lo es para Prévost y Buffon e incluso para el Journal de Trévoux, tanto para De Pauw como para Pernety su testimonio también es sinónimo de autoridad (Duchet 1975, pp. 97-98).

En relación con este último punto, resulta de particular interés señalar que el éxito editorial del que gozaron las obras de La Condamine y su reconocimiento dentro de la República de las Letras respondieron a la forma en la que el propio viajero capitalizó una empresa que, en términos científicos, no había sido en realidad tan auspiciosa. En efecto, el expedicionario francés había partido en 1735 a América como parte de la misión científica francesa destinada a medir un arco de meridiano en el Ecuador, y "determinar así la verdadera forma de la Tierra" (Gerbi 1982, pp. 132-133). Los resultados de esta medición serían luego comparados con las mediciones realizadas en Laponia por una expedición francesa de similares características, liderada en este caso por el matemático Pierre-Louis Maupertuis.

51 Una serie de sucesos desafortunados determinó, sin embargo, que fuese Maupertuis quien primero cumpliera con su propósito y regresara pronto a Europa para ser aclamado por sus logros por todas las academias científicas..$^{33}$ La Condamine, en vez, siguió el curso del Amazonas para volver diez años después desde Guayana a Francia y no recibir más que "la estimación de los sabios y de los filósofos" (Duchet 1975, p. 98). En su Relation abrégée d'un voyage fait dans l'intérieur de l'Amérique méridionale, depuis la Côte de la Mer du Sud jusques aux Côtes du Brésil et de la Guiane, en descendant la rivière des Amazones (1745) y su Journal historique (1751) se encargó, sin embargo, de tratar temas en boga tales como la existencia de las amazonas o la disputa sobre los monumentos y arquitectura del antiguo Perú, que garantizaron el éxito de sus publicaciones y el reconocimiento de su figura como científico y explorador.

52 La prensa periódica, por su parte, también se encargaría de engrandecer las acciones de La Condamine. En efecto, fue gracias a los comentarios que su obra recibió en publicaciones tales como el Journal des Sçavans, la Bibliothèque raisonnée des ouvrages des savans de l'Europe, el Journal de Trévoux y el Mercure de France que "su reputación como 
cartógrafo de precisión, autor talentoso y valiente explorador fue proclamada con vigor tanto dentro de Francia como fuera de ella" (Safier 2008, p. 99). ${ }^{34}$

En lo que refiere al uso de referencias en la Dissertation de Pernety, merece un último comentario la alusión que el benedictino hace del inglés Bristock, que retoma a su vez de la Histoire Naturelle et Morale des Illes Antilles de l'Amérique (1658) de Charles Rochefort. Así como con otros viajeros, Pernety utiliza la crónica que el inglés había supuestamente escrito sobre los apalaches, una tribu que considera superior a otras de la región (Garrison Brinton 1859, p. 94), como testimonio válido para refutar los postulados antiamericanistas de De Pauw.

bien, si el testimonio de este gentilhombre inglés es para Pernety garantía de seriedad, no lo es tanto para De Pauw, quien al momento de refutar la disertación del benedictino critica la elección y veracidad del testimonio de un "hombre oscuro y totalmente desconocido en la República de las Letras" (De Pauw 1770b, p. 171). ${ }^{35}$

En principio, esto se debió a que tanto la naturaleza del testigo como aquello que dice haber visto fueron seriamente cuestionados no solo por De Pauw sino por muchos de sus contemporáneos. El problema radicaba en que, más allá de que los apalaches hubiesen sido mencionados por los primeros españoles en llegar a la península de Florida, el de Bristock es el único testimonio existente sobre la naturaleza superior de esta comunidad indígena. En efecto, la primera crónica propiamente dicha sobre los apalaches fue realizada por Bristock en 1656 e incluida en la obra del abate Rochefort, publicada algunos años después. Al parecer, Bristock había vivido varios años en las Indias Orientales y en América del Norte, dominaba varias lenguas locales y en 1653 había visitado la región en la que esta comunidad estaba establecida.

Rochefort fue el primero en reproducir las notas del viajero inglés en su Histoire Naturelle et Morale des Illes Antilles de l'Amérique, publicada en Róterdam en $1658 \mathrm{y}$, varios años después, las mismas fueron insertadas en la Description de tout l'Univers, en plusieurs cartes, et en divers traités de géographie et d'histoire de Nicolas Sanson d'Abbeville, publicada en Ámsterdam en $1700 .{ }^{36}$ Más allá de esta inclusión más reciente, tal como lo indica el propio Pernety, es de los escritos de Rochefort que obtiene la información que luego cita sobre los apalaches (Pernety 1770b, p. 20).

Al margen de las críticas realizadas por De Pauw, el carácter de las observaciones de Bristock se vuelve aún más cuestionable si se suma a su vez el hecho de que antes de que las mismas fuesen publicadas, tanto la tribu como la región de los Apalaches (ubicada en el norte de Florida y el sudeste de Georgia, en torno al río Apalachicola) se habían convertido en una de las principales motivaciones de las primeras expediciones españolas al sur de los actuales Estados Unidos, que avanzaron hacia el norte desde la península de Florida en la búsqueda de oro y riquezas de todo tipo. ${ }^{37}$ Efectivamente, a partir de su desembarco en Tampa Bay, Florida, en abril de 1528, la expedición española liderada por Pánfilo de Narváez entra en contacto con la comunidad indígena timucúa. Es allí donde se les informa que en la región de Apalache existen grandes riquezas. La búsqueda comienza entonces y solo acaba en septiembre de ese mismo año cuando, exhaustos y habiendo llegado al asentamiento apalache pero no habiendo encontrado las anheladas riquezas, la expedición se detiene en la bahía de Pensacola.

58 En la edición de Naufragios publicada en Valladolid en 1555, la región de Apalache y sus habitantes son mencionados entre el capítulo IV y el VII, en donde son narradas las expectativas iniciales y el posterior desencanto respecto de los bienes que podían 
obtenerse en la región (Núñez Cabeza de Vaca 1992). En efecto, en el capítulo IV Álvar Núñez Cabeza de Vaca explicita los motivos detrás de la búsqueda de Apalache:

Por señas preguntamos a los indios de adónde auían auido aquella cosas [unas porquerías europeas* Señaláronnos que muy lexos de allí auía vna prouincia que se dezía Apalache, en la qual auía mucho oro, y hazían seña de auer muy gran cantidad de todolo que nosotros estimamos en algo (Núñez Cabeza de Vaca 1992, p. 191).

La llegada es narrada en el capítulo siguiente, ${ }^{38}$ donde la expedición encuentra "mucha cantidad de maíz que estaba para cogerse, y mucho seco que tenían encerrado" pero no el oro y las riquezas descriptas por las poblaciones indígenas vecinas (Núñez Cabeza de Vaca 1992, p. 199).

Una comparación entre la imagen que Cabeza de Vaca construye en 1555 de los apalaches y aquella que Pernety retoma de Bristock a través de Rochefort en 1770 permite observar cómo entre los siglos XVI y XVIII la tierra idealizada por los españoles por sus posibles riquezas, es utilizada en el siglo XVIII como representación de un espacio ideal en términos del comportamiento, sensibilidad y razón de sus habitantes. Pernety no presenta a los apalaches como modelo o sinónimo de la abundancia americana sino como ejemplo de buen gobierno y del buen uso de la razón, acaso el requisito de todo pueblo virtuoso en el siglo XVIII. ${ }^{39}$

Las descripciones de Bristock en torno a los apalaches constituyen la última referencia o argumento de peso utilizados por Pernety en su defensa de América, al menos en esta primera parte de la Dissertation. Con otros ejemplos y referencias, los mecanismos de argumentación aquí analizados volverán sin embargo a repetirse a lo largo de sus escritos, convirtiéndose de esta forma en uno de los pilares fundamentales de la "táctica contraofensiva” desplegada por Pernety contra los postulados de De Pauw (Gerbi 1982, pp. 111, 120).

En relación con este último punto, es posible sugerir entonces que el análisis del fragmento seleccionado, la reconstrucción de su contexto de producción y su vinculación con una serie de relatos de viaje contemporáneos permiten inscribir y comprender la obra de Pernety dentro del debate en torno a la naturaleza de América desarrollado a fines del siglo XVIII. Esta mirada de conjunto se presenta a su vez como un aporte o mínima contribución al objetivo más ambicioso de detectar los cambios en la historicidad del concepto de Nuevo Mundo y el lugar que este supo ocupar en el transcurso de la modernidad temprana.

\section{La fuente. Traducción del fragmento seleccionado}

Nota sobre la traducción:

La presente traducción ha pretendido ser fiel al original en francés. Sin embargo, en función de una mejor comprensión del texto, en los casos donde resultó necesario se han modificado los signos de puntuación. Las notas al pie (*) realizadas por el autor en la publicación original se encuentran al final de cada página $\mathrm{y}$, salvo que se indique lo contrario, las palabras que aquí aparecen en cursiva se encuentran en esta tipografía en la versión original.

Página 1 (Título): 
Disertación sobre América y los americanos, contra las investigaciones filosóficas de M. de P***. Por Dom Pernetty, Abad de la Abadía de Bürgel, de las Academias Reales de Prusia y de Florencia, y Bibliotecario de Su Majestad el Rey de Prusia. M.DCC.LXX

Página 3:

Prefacio

Se me había presentado muy positivamente la obra de M. de P. que lleva por título: Investigaciones filosóficas sobre los americanos. Me la procuré, la leí una primera vez bastante precipitadamente, y encontré allí investigaciones, muchas reflexiones muy sensatas, pero también muchas aserciones demasiado aventuradas, por no decir más, presentadas, a la vez, en un tono afirmativo, un estilo vivo y una confianza que, por el tipo de materias que trata, debían imponerse poco a los lectores. Releí esta o-/

\section{Página 4:}

bra con atención, y confirmé mi primera idea. Reconocí que M. de P. o sabe poco de América y de lo que ella contiene, o que, para apoyar la opinión de un autor que había adoptado, sin un conocimiento de causa lo suficientemente fundado, se había puesto como deber criticar todo acerca del nuevo Mundo y sus producciones. He leído y releído cantidad de relaciones sobre América; he visto con mis propios ojos la mayoría de las cosas que son relatadas. Sorprendido de verlas contradichas, o travestidas por M. de P., me contenté de hacer algunas notas sobre los pasajes menos exactos. Mi intención era la de comunicárselas a M. de Francheville, para/

\section{Página 5:}

que las insertara en su gaceta literaria. Dado que esas notas me parecieron luego demasiado numerosas para utilizarlas del modo que me había propuesto, les di cierto orden, y creí poder componer una disertación donde América y aquello que ella contiene serían apreciados en su justo valor. Leí la primera parte en la asamblea de la Academia del siete de septiembre último, y tuve la satisfacción de ver que no se desaprobó la decisión que había tomado de refutar la obra de M. de P., quien habría podido inducir al público al error en ciertos aspectos. La verdad me será siempre estimada; ella debe también serlo para M. de P., y prevalecer sobre cualquier otro motivo. Espero/

\section{Página 6:}

que M. de P. la reconozca en mi Disertación, y que no emplee más que para ella sus talentos, que merecen elogios.

Página 7:

Disertación sobre América y los naturales de aquella parte del mundo.

El Señor de P. acaba de actualizar una obra bajo el título, Investigaciones filosóficas sobre los americanos. Se esfuerza en dar allí la idea más desventajosa del nuevo Mundo y de sus habitantes. El tono afirmativo y decidido con el cual propone y contesta sus preguntas; el tono seguro con el cual habla del suelo y de las producciones de América, de su temperatura, de la constitución corporal y espiritual de sus habitantes, de sus costumbres y de sus usos, en fin, de los animales, podrían hacer creer que ha viajado por todas las regiones de aquella vasta extensión de la tierra;

Página 8:

que ha vivido el suficiente tiempo con todos los pueblos que la habitan. Uno estaría tentado de suponer, que, entre los viajeros que han realizado largas estadías, algunos nos 
contaron fábulas, travistieron la verdad por imbecilidad, o la violaron por malicia. $\left.{ }^{*}\right)$ Los otros, aturdidos por el vértigo de su entusiasmo, vieron tan mal las cosas, que por respeto a la razón, debieran haberse abstenido de describirlas. Es molesto para nosotros que ellos no hayan tenido el respeto por la verdad y los ojos de Mr. de P.

América, dice este autor en su Discurso Preliminar, América más que cualquier otro país, ofrece fenómenos singulares y numerosos; pero fueron tan mal observados, peor descritos y tan confusamente agrupados que no forman más que un caos espantoso. Hizo falta armarse de perseverancia para abrirse camino a través de las contradicciones viciosas de los viajeros, a quienes las extravagancias cuestan menos que al resto de los hombres.

El nuevo Mundo es, siguiendo a Mr. de P. (**) una tierra absolutamente ingrata, y un espanto a la Naturaleza. Entre la vegetación exótica importada a América, los árboles frutales de carozo, como los almendros, los ciruelos, los cerezos, los nogales, allí han débilmente prosperado y casi en absoluto. Los durazneros y albaricoqueros no dieron fruto más que en la isla de Juan Fernández: degeneraron en otros lados; nuestro centeno y nuestro trigo no prendieron más que en algunas partes del Norte. El clima de América era al momento de ser descubierta, muy perjudicial para la mayoría de los cuadrúpedos, y sobre todo pernicioso para los hombres, embrutecidos, enervados y viciados en todas las partes de su organismo con fuerza sorprendente. La toda su superficie, burlando siempre la esperanza de los cultivadores más laboriosos. Todo, hasta los hombres y los animales conducidos del Antiguo Mundo al nuevo, sufrió sin excepción $\left({ }^{* *}\right)$ una alteración sensible, sea en sus fuerzas, sea en su instinto. Como los vegetales, se desmadraron, su tamaño se degradó (***); y por singular contraste los osos, tigres y leones americanos están completamente degenerados, son pequeños, pusilánimes y mil veces menos peligrosos 
Página 10:

que aquellos de Asia y de África.

Es principalmente al clima de América que deben atribuirse las causas que han viciado sus cualidades esenciales; y hecho degenerar la naturaleza humana. $\left(^{*}\right)$ Resulta de las experiencias hechas con criollos, que en su tierna juventud, al igual que los americanos, dan algunas señales de inteligencia, que se extinguen al salir de la adolescencia: se atontan, se vuelven indolentes, desaplicados y no alcanzan a perfeccionarse en ninguna ciencia, ni en ningún arte. También se dice, en forma de proverbio, que ya están ciegos, cuando los otros comienzan a ver.

Hemos considerado hasta ahora, $\left({ }^{* *}\right)$ continúa este autor, a los pueblos de América, que a la par de sus facultades físicas, esencialmente viciadas, también perdieron sus facultades morales. La degeneración habiendo alcanzado sus sentidos; y sus órganos, su alma perdió en la misma proporción que sus cuerpos. La Naturaleza habiendo quitado a un Hemisferio de este Globo, para darle al otro, no ubicó en América más que a niños, los cuales todavía no pudieron hacerse hombres.

Una insensibilidad estúpida constituye la base del carácter de todos los americanos; su pereza les impide estar atentos a las instrucciones; ninguna pasión tiene el poder suficiente para estremecer su alma, y elevarla por sobre sí misma. Superiores a los animales, porque tienen el uso de sus manos y de la lengua, son realmente inferiores al menor de los europeos: privados a la vez de inteligencia y perfectibilidad, no obedecen más que a los impulsos de su instinto: ningún motivo de gloria puede penetrar en su corazón: su

\section{(*) Tom. II, p. 139.}

(**) Tom. I, p. 134.

Página 11:

imperdonable cobardía los retiene en la esclavitud, a donde ella los ha sumergido, o en la vida salvaje, de la que no tienen el coraje de salir --- los verdaderos indios occidentales no encadenan sus ideas: no piensan y les falta memoria. $\left({ }^{*}\right)$

Si hemos descripto a los americanos, dice todavía M. de P., como una raza de hombres, que tienen todos los defectos de los niños, como una especie degenerada del género humano, cobarde, impotente, sin fuerza física, sin vigor y sin elevación de espíritu; más allá de lo indignante y repugnante que sea esta imagen, no hemos dejado nada librado a la imaginación haciendo este retrato ${ }^{* *}$ que sorprenderá por su novedad, ya que la historia del hombre natural ha sido más relegada de lo que se cree. En fin, América es a los ojos de M. de P. una tierra que la Naturaleza parece haber hecho encolerizadamente, para la cual ha vertido con complacencia todos los males, todas las amarguras de la caja de Pandora, sin dejar escapar la más mínima porción de los bienes que ella encerraba.

Tal es el bosquejo del retrato de América y de sus habitantes que M. de P. nos presenta. Ha extraído sus colores, dice él, tanto como fue posible, de los autores contemporáneos del descubrimiento del Nuevo Mundo, que pudieron verlo antes de que haya sido enteramente transformado por la crueldad, la avaricia y la avidez de los europeos.

A este retrato, en donde fácilmente podría creerse que el pintor ha mojado su pincel en el humor negro de la melancolía y diluido sus colores en la hiel

(*) Tom. I, p. 117. 
(**) Discurso Preliminar.

\section{Página 12:}

de la envida; donde todos los trazos parecen haber sido ubicados y conducidos, no por la filosofía que anuncia haber presidido su obra, sino por un amor propio ofendido, por haber tomado partido por humillar la naturaleza humana; ¿me sería permitido, Señores, presentarles uno de los mismos objetos, que por ser más risueño y más halagüeño, no será menos cierto $?^{40}$

Si M. de P. hubiese viajado a América y la hubiese recorrido en persona, la hubiera conceptuado y observado verdaderamente con otros ojos. No hubiese hecho su libro, a menos que hubiese tomado partido por disfrazar la verdad, traicionarla algunas veces, y de contradecirla en donde sea que la encontrara. ¿Podría hacérsele ese reproche a M. de P.?, ¿a él, cuya obra parece ser el fruto de tantas preocupaciones, lecturas y reflexiones? No, no me atrevería a pensarlo; pero ¿no podríamos considerarlo sospechoso de haber hecho muchas lecturas demasiado precipitadamente, de haber leído y visto las cosas con los ojos mal prevenidos, desinteresados; de no haber extraído y agrupado más que aquello que encontró apropiado para sostener una hipótesis creada por una imaginación un poco demasiado embriagada de simpatía por nuestro Hemisferio y por sus habitantes? No debe creerse lo suficientemente privilegiado como para estar exento de los prejuicios de la educación, que presentan tantos obstáculos a la verdadera filosofía. La precaución crece con la edad; la educación nos inspira errores:, nos da gustos que se fortifican cada vez más; nos acostumbramos a los usos; estos nos placen e influencian tanto nuestra forma de ver y de pensar que creemos ver a través de los ojos de la filosofía, cuando no vemos más que a través de aquellos de la educación: no encontramos buenos ni bellos los usos de otros países más que cuando se hallan en cierta conformidad con los nuestros. El pan, el vino, nuestros platos y sus preparaciones ¡son cosas tan buenas! ¿No es ser imbécil, estúpido,

\section{Página 13:}

mantenerse a raíz de mandioca, chica, frutas, papa, carnes de animales y pescados ahumados? Hacemos hablar así a nuestra educación bajo el nombre de la filosofía. Sin embargo, al mirar con atención nuestro Hemisferio, o todo lo que abarca eso que llamamos el antiguo Mundo, con ojos verdaderamente filosóficos, M. de P. hubiese visto que la Naturaleza no quitó todo a América para dárselo a nuestro continente. Hubiese visto en este a los lapones, samoyedos, tártaros, ocupados en la caza de animales para encontrar su alimento y sus vestimentas; un clima librado al frío más vivo y más vigoroso, donde ni las frutas ni los granos ni los árboles mismos pueden germinar; donde los hombres, mil veces más miserables, según nuestra forma de pensar, de lo que lo son tres cuartos y medio de los pueblos de América, no ofrecen a nuestros ojos más que el espantoso espectáculo de una tierra maldita, y la naturaleza humana así como la animal están absolutamente degradadas. Por otra parte, los desiertos arenosos y ardientes de África, ese horno donde los hombres irritados parecen, por su color, ser la víctima y la presa del fuego que la Naturaleza allí mantiene siempre encendido.

1 Si examino nuestros climas templados, encuentro montañas áridas; siempre, o quemadas por los rayos del sol o libradas al furor de los fríos del norte; veo sus cumbres amenazar al cielo, y compadecerse de no haber visto aún sus cabezas altivas despejadas de la inmensa carga de hielos y de nieves que las cubren. 
112 Veo allí, a decir verdad, llanuras risueñas y agradables, donde el dulce murmuro de los arroyos se une al canto agraciado de los pájaros para halagar nuestro oído, mientras que nuestro olfato es hechizado y nuestros ojos encantados de ver allí esas llanuras esmaltadas de flores, cubiertas de granos, de árboles frutales, y de rebaños. ¿Pero qué producirían ellas por sí mismas? Zarzas y espinas, algunas

Página 14:

frutas silvestres, cuyo sabor repugnante las haría ser abandonadas a los animales, que las desdeñarían. ¿Están aquellos países de América expuestos a los mismos paralelos que los nuestros, esos países donde las flores más suaves nacen sin cesar bajo vuestros pasos, y donde las frutas más excelentes crecen en la mayor abundancia, y sin cultivar?

¿Qué privilegio tiene entonces nuestro continente sobre aquel de América? El de estar habitado por hombres condenados a un trabajo sin descanso; obligados, para satisfacer sus necesidades más urgentes, a comer incluso el pan menos apetitoso, a regar sin cesar con su sudor y su llanto esta tierra, juguete de un clima inconstante, esta tierra que frecuentemente frustra sus esperanzas, y cuya belleza risueña es efecto no de una naturaleza ávida, como en América, de satisfacer los deseos de sus hijos:, sino de una naturaleza forzada a reírse con una mueca convulsiva, con la que nuestro orgullo y nuestro amor propio ha sabido aprender a contentarse, e incluso, a encontrarla bella.

No es a los hombres vestidos de oro y de púrpura, cuya indolencia apáticamente extendida sobre el edredón se burla de las injurias del aire bajo revestimiento del oro y de la lazulita”, que no abren los ojos más que para ser deslumbrados por el resplandor del lujo del que están rodeados, y no estiran las manos más que hacia platos preparados para excitar su apetito embotado, o para dar placer a sus sentidos, a expensas de la vida y del trabajo de esos hombres que gimen bajo el peso de su cruel tiranía:, sino a estos últimos a quienes hay que consultar: a ellos corresponde comparar el estado del suelo en América y de sus habitantes con el estado y el valor de nuestro Continente. ¿Creen ustedes, Señores, que si estuvieran perfectamente instruidos, dirían junto a M. de P. que la Naturaleza los ha privilegiado; que ella ha quitado todo a América para dárselo a la tierra en donde ellos habitan?

\section{Página 15:}

¿Lo pensarán ustedes, ustedes mismos, del retrato inocente, sincero que voy a trazarles luego en base al informe de autores verdaderos, y sobre lo que vi yo mismo? Del retrato pretendidamente filosófico de M. de P. podrán decir conmigo luego aquello que él dice $\left(^{*}\right)$ de los historiadores españoles sobre el tema de Perú; lamentablemente, todo ese retrato, cuando se lo examina con atención, no es más que una ficción, una sarta de mentiras y de exageraciones, que nos hemos acometido refutar para ajustarnos a las leyes de la historia, que quiere que se destruyan todos los errores engañosos que podrían convertirse en verdades históricas, si continuáramos adoptándolas ciegamente.

No es sorprendente encontrar relaciones diferentes entre sí sobre el mismo país y sobre los mismos pueblos: fueron escritas en diferentes tiempos; las usanzas habrían podido cambiar, así como la superficie del suelo, por la frecuentación de los europeos que allí se establecieron. Los naturales del país se acomodaron con frecuencia a las formas de vivir y de proceder de sus nuevos anfitriones; o dejaron por completo sus antiguas prácticas, o las modificaron en parte: así también con sus antiguas costumbres. Hay que atenerse a las relaciones antiguas y darles preferencia sobre las nuevas cuando tienen las tres condiciones requeridas para una buena historia: que hayan sido compuestas por Autores 
desinteresados en sus relatos; que esos autores no hayan querido burlarse de la verdad; y que a una buena memoria sumen bastante inteligencia y espíritu para contar aquello que han visto. Aquellos que citaré están exentos de reproches en este sentido. Puede contarse con los extractos que contrastarán la descripción sobre América que nos ha presentado M. de P. Condamine, no se puede negar al ver las diferentes ruinas que se encuentran hoy en día en diferentes sitios de Perú que esos pueblos, más allá de no haber tenido uso del hierro ni ningún conocimiento mecánico según declaran todos los historiadores, no hayan encontrado la forma de transportar, elevar y ensamblar con mucho arte, piedras de un tamaño prodigioso y frecuentemente de forma irregular. El P. Acosta, testigo ocular, asegura que esas masas no pueden ser vistas sin asombro; y dice haber medido él mismo en las ruinas de Traguanaco (sic por Tiahuanaco), una piedra de 38 pies de largo, sobre 18 de ancho y 6 de profundidad, y que allí había muchas aún más grandes." Decir que hicieron todo eso con mucho arte es, en mi opinión, reconocer que los peruanos tenían algunos conocimientos de mecánica. Las pruebas que M. de la Condamine da luego de su 
habilidad en las artes, de su pericia en la ejecución de piezas de escultura, de orfebrería, etc. destruyen por igual la idea que M. de P. se esfuerza en vano de inspirarnos acerca de la crasa ignorancia, la torpeza, la ineptitud y la extraña indolencia de los americanos. Es desde lo que ha visto con sus propios ojos que M. de la Condamine va a hablarles. Me veo en la obligación de prevenir al lector, dice este erudito, cuya sinceridad iguala sus vastos conocimientos; me veo en el deber prevenir al lector que la descripción que voy a hacer de las ruinas vecinas de Cannar, puede dar una idea de la na-

(*) Ibid., p. 151.

\section{Página 18:}

turaleza, la forma y tal vez la solidez de los palacios y de los templos edificados por los Incas, pero no de su extensión ni de su magnificencia.

Había entonces en Perú ciudades, palacios, templos, cuyos materiales habían sido transportados, elevados y ensamblados con mucho arte; palacios y templos de una magnificencia de la que aún la descripción de M. de la Condamine no puede dar idea; ciudades de vasta extensión, cuyos nombres y ruinas subsisten en parte, de las que un extremo está todavía ocupado por los indios, según el informe del padre Feuillé y de Frézier. No daré aquí la descripción de $\mathrm{M}$. de la Condamine, se la puede leer en la memoria misma. Se verá allí que $\mathrm{M}$. de P. es un poco demasiado exigente; y que más de tres cuartos y medio de las grandes ciudades del mundo no serían al parecer de M. de P. más que un conjunto de miserables cabañas, que apenas merecerían el nombre de aldeas.

4 Los autores que he citado las observaron sin duda con mucha atención; ya que ¿cómo hombres estúpidos, indolentes, degenerados de la naturaleza humana, a quienes no queda más que la figura, y a quienes la Naturaleza por gracia y por piedad quiso dejarles el instinto; cómo estos animales que no eran superiores a los otros más que por el uso de la lengua y de las manos, pudieron haber tenido la idea de edificar otras viviendas que no fuesen guaridas, o más que cabañas, para protegerse de las inclemencias del aire y de la cruel voracidad de las bestias feroces ${ }^{41}$ ? $\mathrm{M}$. de la Condamine y muchos otros fueron embargados de admiración al ver producciones de ese instinto, que tenía cosas tan bellas como la industria y la habilidad de nuestros mejores obreros. Ya que para dar esa convexidad regular y uniforme a todas las piedras, dice M. de la Condamine, y para pulir tan perfectamente las caras internas a través de las cuales se tocan, ¿qué trabajo, qué industria debió su-

\section{Página 19:}

plantar nuestros instrumentos, en estas gentes que no tenían ninguna herramienta de hierro, y que no podían tallar piedras más duras que el mármol más que con hachas de piedra, ni aplastarlas más que utilizándolas mutuamente para el frotamiento? Esas piedras son una especie de granito, y no hay ningún cemento en las juntas. Se tiene la impresión de que la falta de hierro y de acero debió limitarlos con frecuencia---Felizmente, superaron esos obstáculos ---- El más hábil tallador de piedras en Europa, tenga la pericia que tenga, estaría sin duda en muchos aprietos si tuviera que cavar de tal forma un canal curvo y regular en el espesor del granito con todo el auxilio del arte y los mejores instrumentos de hierro y de acero: con más razón todavía será difícil imaginar cómo los antiguos peruanos pudieron lograrlo con sus hachas de piedra o de cuero, tal como las que se encontraron en las antiguas tumbas, o con otras herramientas equivalentes y sin escuadra ni compás. 
137 Pero ese instinto, si hemos de creerle a M. de P., no había siquiera enseñado a los americanos a hacer ladrillos, y construir sus casas. Sin embargo, en Perú y en Chile los materiales comunes de los edificios particulares estaban hechos de lo que ellos llaman adobes, es decir, ladrillos de más o menos dos pies de largo sobre uno de ancho, y cuatro pulgadas de espesor para el caso de Chile: aquellas de Perú estaban hechas de un molde más pequeño, a causa, dice Frézier, de que jamás llueve.

138 Es cierto que algunas ruinas de los edificios construidos por los indios presentan muros construidos con tierra colocada entre dos planchas en forma de grandes ladrillos, una manera de levantar muros que no era solamente utilizada en América, ya que Viturbo nos enseña que los romanos también edificaban de esta forma. Todavía es la práctica de muchas provincias de Francia, donde se llama a esos muros, muros de Piset. Se los utiliza también $\left({ }^{*}\right)$ esos hombres estúpidos a los ojos de Mr. de P. eran a aquellos de Frézier gente, dice, extremadamente industriosa en conducir las aguas de los ríos a sus viviendas. Aún en 1713 se observan acueductos de piedras secas y de tierra, llevados y desviados ingeniosamente a lo largo de las laderas por una infinidad de pliegues y recodos; lo que demuestra que esos pueblos, tan ordinarios como eran, entendían muy bien el arte de la nivelación. Aún puede observarse aquello que el P. Feuillée y el Señor Ulloa dicen de las ruinas de las antiguas ciudades de Perú. recusaría su testimonio. Pero no creo que haga lo mismo con aquel de Mr. Bristock, gentilhombre inglés. Aquellos de esa nación no tienen la costumbre de embellecer sus relaciones. Los americanos conocidos bajo el nombre de apalaches no eran ni más brutos ni más estúpidos que aquellos de Perú. Mr. de P. hubiese admirado, dice, el gobierno, las leyes de los Incas y la felicidad de los peruanos, si todo eso hubiese existido. Que lo admire entonces en los apalaches. El Señor Bristock estuvo en su país en 1653, y permaneció allí el suficiente tiempo como para ponerse al corriente de sus antiguas y sus nuevas usanzas. Su relación constituye los capítulos 7 y 8 del segundo libro de la historia natural y moral de las islas Antillas del Caballero Rochefort. Nos enseña que Perú y México no eran los únicos países del nuevo continente donde hubo antiguamente ciudades. Aquel de 
igual que el interior. El pavimento está unido como el mármol, pulido todo en una pieza, habiendo sido todo cavado en la roca.

Página 22:

Página 23:

Al pie de esta montaña, pueden verse aún hoy las tumbas de muchos de sus reyes, talladas en la piedra y delante de cada una de las cuales se eleva un cedro para indicar el sitio.

Las casas de los apalaches están todas construidas con vigas, o piezas de madera muy bien ensambladas, y ligadas las unas a las otras. Los techos son de hojas de caña o de junco, tal como lo son de paja aquellos de muchos sitios de Europa. Aquellas de los jefes y de los principales están untadas de una resina que resiste la lluvia. El piso está hecho del mismo cemento. Utilizan una arena dorada que produce un efecto maravilloso, y da un brillo admirable. Sus apartamentos están tapizados de esteras tejidas con hojas de palma y de junco, teñidas de diversos colores, y ordenadas por compartimentos. Las habitaciones de los jefes están tapizadas de pieles, o de pieles de ciervos pintadas, representando diversas figuras. Algunas están decoradas con plumas

de pájaro muy industriosamente arregladas en forma de bordado.

He aquí entonces al menos tres países muy considerables de América, donde los naturales no vivían en hordas de familias dispersas y vagabundas. Una colonia francesa fue a establecerse con los apalaches, bajo la dirección del Capitán Ribaut y bajo los auspicios de Carlos IX. Es por ello que esta nombró Carolina a la especie de fortaleza que allí elevó. Ribaud dio a los puertos y a los ríos de aquel país los nombres de puertos y ríos de Francia, que se conservan todavía hoy. Esta colonia encontró a los apalaches tal como los va a describir M. Bristock.

Todo ese país está dividido en seis provincias, tres de las cuales, Bémarin, Amani y Matiqué, ocupan uno de los más bellos y espaciosos valles rodeado de montañas de Apalates ${ }^{43}$. Las otras tres son Schama, Méraco y Achalaques, que se extienden en las montañas. Los habitantes de aquellas no viven más que de la caza. El valle tiene sesenta leguas de largo y diez de ancho. Las ciudades y pueblos están construidos sobre las pequeñas atalayas; el país abunda en madera de todo tipo, en frutas, legumbres, hierbas de huerto, mijo, maíz, lentejas, arvejas, etc., cuadrúpedos, pájaros de todo tipo. Los hombres allí tienen una gran estatura, están bien constituidos, conforman un pueblo cuyas costumbres son dulces, viviendo en sociedad en las ciudades y las aldeas y en la más grande unión. Todos los inmuebles son comunes entre ellos, excepto sus casas y sus jardines. Como cultivan sus campos en común, comparten sus frutos, después de haberlos depositado en los graneros públicos ubicados en el medio de cada ciudad y pueblo. Aquellos que están encargados de la distribución, la hacen cada vez que se renueva la luna y dan a cada familia, según la cantidad de personas que la componen, tanto como lo que necesitan.

La unión es tan grande entre ellos, que en la misma casa puede verse a un anciano con sus hijos y sus nietos, hasta la cuarta generación, en una cantidad de cien personas y a veces más. Son de naturaleza muy amable, no sabiendo qué caricias hacer a los extranjeros cuando los reconocen como amigos, y presentando todo lo que tienen, en la forma en que lo hacen los grandes Tártaros y los Circasianos, por el solo placer de complacer. El mismo espíritu de hospitalidad se encuentra en casi todas las otras naciones de América, incluso entre los brasileños, que han pasado por ser los menos humanos. Es otra cosa más que la Naturaleza no ha quitado a América para dar a Europa; ya que nosotros no tenemos más 
que la máscara muy imperfecta de la verdadera hospitalidad y los americanos la tienen en realidad en toda su extensión.

Los apalaches aman apasionadamente la música y los instrumentos; que generan alguna armonía. Casi todos tocan la flauta y una especie de oboe. Están perdidamente enamorados de la danza y realizan mil posturas singulares con la idea de que este ejercicio disipa todos los humores, les da gran flexibilidad para la caza y mucha agilidad para la carrera.

Su voz es dulce, bella y flexible. Trabajan en la imitación del canto de los pájaros y lo logran perfectamente. Su lenguaje es dulce, sus expresiones enérgicas y precisas, sus pausas lacónicas. Desde pequeños aprenden las canciones compuestas por los Jouas ${ }^{44}$ en honor al sol, como padre de la Naturaleza, e incluyen los relatos de las hazañas de sus jefes para perpetuar la memoria. de frecuentarse desde hace tiempo, aquellas no cambiaron en nada su forma de vivir, sus usos, ni la forma de sus vestimentas. Sus camas están elevadas un pie y medio de la tierra, arriba durante el verano y llevaban abrigos forrados durante el invierno. Hoy en día, la mayoría tiene, en verano, vestimentas de una tela liviana de algodón o de una hierba preparada e hilada como el lino. Ordinariamente los hombres y las mujeres no llevan más que una casaca sin mangas sobre un pequeño traje de gamuza muy fino. Esta casaca desciende hasta el muslo en los hombres, y hasta el tobillo del pie de las mujeres. Está sujeta a la cintura por un cinturón de piel o cuero, trabajado y adornado con una pequeña obra en forma de bordado. Los jefes de familia utilizan por encima un manto que no les cubre más que los hombros, la espalda y los brazos; pero que termina por detrás en una punta alargada hasta la tierra y genera casi el mismo efecto que las chalinas que nuestras damas francesas todavía vestían a principios de este siglo. A estas últimas, le sucedieron las capas en algunos países y la manteleta en otros. Los hombres y las mujeres apalaches están todos interesados en mantener su cabellera siempre limpia y muy bien trenzada. Las mujeres la acomodan en forma de guirnalda sobre la cabeza; los hombres se cubren con gorros de piel de nutria negros y lustrosos, cortados en punta por adelante, decorados detrás por bellas plumas de pájaro, organizadas de forma tal que una parte de este

Para Página 25:

penacho desciende sobre los hombros. Las mujeres se perforan las orejas y colocan allí pendientes de cristal o de una piedra verde, que tiene el brillo de la esmeralda. También hacen con ella collares y pulseras, para vestirlos los días de fiesta, al igual que el coral y el ámbar amarillo que hoy en día estiman mucho. cuyo olor es tan suave como el del iris de Florencia. Ese jugo tiene además la propiedad de dar flexibilidad a los nervios y a los músculos, suavizar la piel, darle brillo y fortificar 
todos los miembros. El ejercicio y esas unciones sumadas a una gran sobriedad, les procuran una salud firme y vigorosa que desmiente la pretendida degradación que M. de P. atribuye a todos los americanos.

Más allá de que la viña crezca naturalmente en lo de los apalaches, su bebida habitual es el agua pura; pero en los festines de pompa y fiestas, beben una especie de cerveza hecha de maíz, o de un aguamiel tan bueno, que se lo tomaría por vino en España. Algunos pueblos de América Septentrional tienen la reputación de ser muy perezosos: pero los apalaches le tienen horror a la ociosidad; el trabajo produce abundancia. Cuando el tiempo de la siembra y de la cosecha ha pasado, todos los hombres y las mujeres se ocupan de hilar algodón, lana o la hierba de la que hablé. Fabrican lonas y telas. Otros hacen alfarería de cerámica esmaltada en diversos colores y jarrones de madera que pintan maravillosamente; otros en fin hacen cestas, canastas y muchas obras con una destreza maravillosa.

Además de los castaños y los noguerales, que crecen naturalmente en aquel país, pueden verse naranjos, limoneros, diversas especies de manzanas, cerezas, damascos, que los ingleses

Página 26:

llevaron y que se multiplicaron de tal forma que abundan para probarle, parecería, a M. de P. que no todo degenera en el suelo de América y que este no es tan ingrato como él quisiera hacernos creer.

franceses que regresaron de Luisiana también le demostrarían por su propia experiencia que aquél país es de los más sanos, de los más fértiles y de los más bellos del mundo. Es el testimonio que muchos de entre ellos me dieron, lamentándose del hecho de que Francia lo ha cedido a España. Tal decepción es verdaderamente uno de los motivos que determinaron a los franceses que allí se quedaron a hacer todos sus esfuerzos por sacudirse del yugo de la dominación española y regresar bajo aquella de Francia.

He aquí entonces, Señores, un pueblo civilizado en América, viviendo en ciudades y pueblos antes de la llegada de los europeos; ciudades de las cuales no solamente se ha conservado el nombre sino que existían aún en 1653, cuando Bristock realizó su estadía. Me gustaría más creer que M. de P., no habiendo leído ni visto todo, ha ignorado su existencia, antes que pensar que ha querido, contra la verdad, destruir hasta la memoria. Aquellas de México y de Perú desaparecieron de delante de sus ojos, no vio en sus ruinas más que chozas. El padre Feuillée, o tuvo mejores ojos o no tuvo el talento de M. de P. para hacerlas desaparecer cuando se acercó a ellas. Nos enseña que había todavía en su tiempo (en 1709) en el camino de Callao a Lima, en las bellas planicies que lo bordean, vestigios de una antigua ciudad indígena que los españoles destruyeron y que tenía hasta cinco leguas de largo; que un reducido número de indios ocupaban aún uno de sus extremos. Si un terreno de cinco leguas de largo, cubierto de casas, merece apenas el nombre de aldea, según M. de P., Nanquin, que, se dice, ocupa casi quince leguas, será entonces

Página 27:

tal vez la única a la cual le hará el favor de dar el nombre de ciudad.

171 El retrato que acabamos de hacer de los apalaches y de su país es muy apropiado para revertir la idea desfavorable que este autor intentó dar de América y de sus habitantes naturales. Esta especie de República o de Reino de los apalaches, donde reina una entera 
libertad, parece incluso superior a aquella de los indios sometidos por los Jesuitas en el Paraguay, y no le parecerá menos quimérica a M. de $\mathrm{P}$.

El dirá, para sostener su aserción, que la relación de M. Bristock es una fábula, una sarta de mentiras, como lo dijo de las relaciones españolas (entonces le responderé con aquello que él mismo dijo: *) negar todo lo que se lee en las relaciones más verídicas o menos sospechosas de los Ata-apas de Luisiana, de los antiguos Caribes de las islas, de los Tapuiges de Brasil, de los Cristianaux, de los Pampas, de los Peganchez, de los Moxas, sería establecer un pirronismo histórico insensato.

Después de tamaña confesión, aquellos que vieron esas relaciones ¿no se hallaron sorprendidos de verlas tratadas de quimeras y de falsedades en toda la obra de este autor? Permítanme, Señores, que ponga delante de sus ojos algunos extractos sucintos de esas relaciones que no han sido puestas bajo sospecha. Para dar cierto orden, las distribuiré en cuatro parágrafos. El primero tendrá por objeto la calidad del suelo de América; el segundo las cualidades personales físicas; el tercero las cualidades morales de sus habitantes; y el cuarto aquellas de los animales, sean naturales del país o transportados desde Europa.

\section{BIBLIOGRAPHY}

Achim, M. (2007). Science in Translation: the Commerce of Facts and Artifacts in the Transatlantic World. Journal of Spanish Cultural Studies, 8 (2), Julio, 107-115.

Achim, M. (2008). La querella por el temperamento de México: meteorología, hipocratismo y reformas urbanas. En F. Gorbach y C. L. Beltrán (Comps.), Saberes locales: ensayos sobre historia de la ciencia en América Latina (pp. 235-261). México: el Colegio de Michoacán.

Bleichmar, D., De Vos, P., Huffine, K., Sheehan, K. (Eds.). (2009). Science in the Spanish and Portuguese Empires, 1500-1800. Stanford, California: Stanford University Press.

Bourguet, M-N., Licoppe, C. (1997). Voyages, mesures et instruments: une nouvelle expérience du monde au Siècle des lumières. Annales. Histoire, Sciences Sociales, 52 (5), 1115-1151.

Bret, P. y Chappey, J. L. (2012). Spécialisation vs encyclopédisme? La Révolution française [en línea], 2/2012. Disponible en: http://lrf.revues.org/515

Cañizares Esguerra, J. (2004). Iberian science in the Renaissance: ignored how much longer? Perspectives on Science, 12, 86-124.

Cañizares Esguerra, J. (2007). Cómo escribir la historia del Nuevo Mundo. Buenos Aires: Fondo de Cultura Económica.

Cicerchia, R. (2000). De diarios, mapas e inventarios. La narrativa de viaje y la construcción de la modernidad. 19th International Congress of Historical Sciences, University of Oslo, 6-13 de agosto.

De Certeau, M. (2007). El lugar del otro. Historia religiosa y mística. Buenos Aires: Katz. 
De Pauw, C. (1768). Recherches philosophiques sur les Américains, ou Mémoires intéressants pour servir à l'histoire de l'espèce humaine. París: s.d.

De Pauw, C. (1770a). Recherches philosophiques sur les Américains, ou Mémoires intéressants pour servir à l'histoire de l'espèce humaine. Berlín : s.d.

De Pauw, C. (1770b). Défense des Recherches Philosophiques sur les Américains par M. De P.***. Berlín: George Jacques Decker.

Duchet, M. (1975). Antropología e historia en el Siglo de las Luces. México: Siglo XXI.

Ette, O. (2010). Arqueología de la globalización. La reflexión europea en dos fases de globalización acelerada en Cornelius de Pauw, Georg Forster, Guillaume Thomas Raynal y Alexander von Humboldt. En R. Sagredo Baeza (Comp.), Ciencia-Mundo. Orden republicano, arte y nación en América (pp. 21-66). Santiago de Chile: Editorial Universitaria-Centro de Investigaciones Diego Barros Arana.

Ette, O. (2014). Palabras-dominios-genealogías. Cornelius de Pauw y la Disputa por un Mundo Nuevo. Telar. Revista del Instituto Interdisciplinario de Estudios Latinoamericanos, IX (11-12), 30-66. García Cárcel, R. (1998). La leyenda Negra: historia y opinión. Madrid: Alianza.

Garrison Brinton, D. (1859). Notes on the Floridian Peninsula. Its Literary History, Indian Tribes and Antiquities. Massachusetts: Applewood Books.

Gerbi, A. (1982). La disputa del Nuevo Mundo. Historia de una polémica, 1750-1900. México: Fondo de Cultura Económica.

Gil Fernández, J. (1989). Mitos y utopías del descubrimiento. Madrid: Alianza Editorial.

Kwiatkowski, N. (2014). Representaciones de la barbarie europea y americana durante los siglos XVI y XVII. Prismas. Revista de historia intelectual, 18, 29-62.

Hartog, F. (2003). El espejo de Heródoto. Ensayo sobre la representación del otro. Buenos Aires: Fondo de Cultura Económica.

Léry, J. (1578). Histoire d'un voyage fait en la terre du Bresil, autrement dite Amérique. La Rochelle: Antoine Chuppin.

Lestringant, F. (1993). The Philosopher's Breviary: Jean de Léry in the Enlightenment. En S. Greenblatt (Ed.), New World Encounters (pp. 127-138). Berkeley y Oxford: University of California Press.

Lestringant, F. (1994). Le Cannibale. Grandeur et décadence. París: Perrin Col. Histoire et décadence.

Martínez, C. (2011). En torno a la idea de naturaleza en el siglo XVIII y el impacto que el descubrimiento del Nuevo Mundo ejerció sobre ella. En M. J. Gandini, M. López Palmero, C. Martínez, R. C. Paredes, Dominio y reflexión. Viajes reales y viajes imaginarios en la Europa moderna temprana (siglos XV a XVIII) (pp. 187-214). Buenos Aires: Editorial de la Facultad de Filosofía y Letras, Universidad de Buenos Aires.

Martínez, C. (2013). Tras las huellas de una singular experiencia colonial: la Francia Antártica en los orígenes de la modernidad temprana europea. En M. J. Gandini, M. López Palmero, C. Martínez, R. C. Paredes, Fragmentos imperiales. Textos e imágenes de los imperios coloniales en América (Siglos XVI-XVIII) (pp. 47-68). Buenos Aires: Biblos.

Meillassoux-Le Cerf, M. (1988). Dom Pernety. Histoire, économie et société, 7 (2), 285-289. 
Meillassoux-Le Cerf, M. (1993). Dom Antoine-Joseph Pernety et son milieu (1716-1796): contribution à $l$ 'histoire de la sensibilité et des idées dans la seconde moitié du XVIIIème siècle. París: Atelier National de Reproduction des Thèses de l'Univ. de Lille 3.

Nieto Olarte, M. (2003). Historia natural y la apropiación del Nuevo Mundo en la Ilustración española. Bull. Inst. fr. études andines, 32 (3), 417-429.

Nieto Olarte, M. (2007). Orden natural y orden social: ciencia y política en el Semanario del Nuevo Reyno de Granada (Vol. 43). Editorial CSIC-CSIC Press.

Núñez Cabeza de Vaca, A. (1992). Los Naufragios. Madrid: Editorial Castalia.

O'Gorman, E. (2003). La invención de América: investigación acerca de la estructura histórica del nuevo mundo y del sentido de su devenir. Buenos Aires: Fondo de Cultura Económica.

Onfray, M. (2009). Los libertinos barrocos. Contrahistoria de la filosofía, III. Barcelona: Anagrama.

Panckoucke, C. J. (1782). Encyclopédie méthodique par ordre des matières. París: Panckoucke.

Paredes, R. C. (2011). Naturaleza colonial y experiencia bucanera. El conocimiento de América y los aventureros ingleses (1650-1700). En M. J. Gandini, M. López Palmero, C. Martínez, R. C. Paredes, Dominio y reflexión. Viajes reales y viajes imaginarios en la Europa moderna temprana (siglos XV a XVIII) (pp. 103-126). Buenos Aires: Editorial de la Facultad de Filosofía y Letras, Universidad de Buenos Aires.

Pernety, A.-J. (Dom) (1770a). Histoire d'un voyage aux isles Malouines, fait en 1763 \& 1764; avec des observations sur le détroit de Magellan, et sur les Patagons, Par Dom Pernetty, Abbé de l'Abbaye de Burgel, Membre de l'Académie Royale des Sciences \& Belles Lettres de Prusse; Associé Correspondant de celle de Florence, \& Bibliothécaire de Sa Majesté le Roi de Prusse. París: Saillant \& Nyon, Delalain.

Pernety, A.-J. (Dom) (1770b). Dissertation sur l'Amérique et les Américains contre les Recherches philosophiques de M. de $P^{* * *}$. Berlín: s.d.

Pernety, A.-J. (Dom) (1771). Examen des "Recherches philosophiques sur l'Amérique et les Américains" et de la "Défense" de cet ouvrage. Berlín: G. J. Decker.

Pernety, A.-J. (Dom) (2012). Historia de un viaje a las Islas Malvinas. Buenos Aires: Eudeba, Colección Reservada del Museo del Fin del Mundo.

Pimentel, J. (2000). The Iberian Vision: Science and Empire in the Framework of a Universal Monarchy, 1500-1800. Osiris, $2^{\text {nd }}$ Series, Vol. 15, Nature and Empire: Science and the Colonial Enterprise, 17-30.

Pimentel, J. (2003a). Testigos del mundo: ciencia, literatura y viajes en la Ilustración. Madrid: Marcial Pons Historia.

Pimentel, J. (2003b). Impostores y testigos: verosimilitud y escritura en las relaciones de viaje. En J. L. Barona, J. Moscoso, J. Pimentel (Comps.). La Ilustración y las ciencias: Para una historia de la objetividad (pp. 237-252). Valencia: Universitat de València.

Pratt, Marie Louise (1992). Imperial Eyes. Travel Writing and Transculturation. Londres y Nueva York: Routledge.

Podgorny, I., Penhos, M., Navarro Floria, P. (Comps.). (2009). Viajes: espacios y cuerpos en la Argentina del siglo XIX y comienzos del XX. Buenos Aires: Investigaciones de la Biblioteca Nacional, Teseo.

Raimondo, F. (2013). La conformación de la colección de viajeros de la Biblioteca del Museo Etnográfico y sus usos pasados y presentes. Encuentro Nacional de Instituciones con Fondos Antiguos y 
Raros, Biblioteca Nacional de la República Argentina "Mariano Moreno", 17 a 20 de abril. Disponible en:

http://www.bn.gov.ar/media/page/raimondo-laconformacion.pdf

Safier, N. (2008). Measuring the New World. Enlightenment Science and South America. Chicago y Londres: The University of Chicago Press.

Valverde Pérez, N. (2007). Actos de precisión: instrumentos científicos, opinión pública y economía moral en la ilustración española (Vol. 47). Editorial CSIC - CSIC Press.

Waquet, F. (1989). Qu'est-ce que la République des Lettres? Essai de sémantique historique.

Bibliothèque de l'école des chartes, tomo 147, pp. 473-502.

Zantrop, S. (1997). Colonial Fantasies: Conquest, Family and Nation in Precolonial Germany, 1770-1870.

Durham: Duke University Press.

\section{NOTES}

1. Sobre la participación de determinados sectores dentro de la élite criolla en el debate en torno a la naturaleza de América véase Gerbi, A. (1982, p. 243-291). Por su parte, Miruna Achim (2008) ha trabajado particularmente sobre la figura del sabio novohispano José Antonio de Álzate y el valor de su condición de "testigo presencial" contra el alegato de inferioridad del hombre americano proclamado por De Pauw, entre otros europeos.

2. Por su parte, en sus Recherches philosophiques sur les Américains... (1770) Cornelius De Pauw aseveraba que, luego de devastar América, los españoles jamás habían mostrado "la más mínima curiosidad en reunir los restos de ese edificio prodigioso: contentos de haberlo demolido con sus manos avaras, descuidaron las ruinas, en parte ocultas bajo los arbustos, en parte dispersas sobre una superficie inmensa" (p. XII). Aquella "leyenda negra" orquestada por Francia e Inglaterra para denostar los logros y contribuciones de la monarquía española en materia científica pervive en los debates historiográficos contemporáneos y ha sido vivamente combatida por historiadores tales como Juan Pimentel (2000), Jorge Cañizares Esguerra (2004) o Miruna Achim (2007). También se destaca la reciente compilación de Bleichmar, D., De Vos, P., Huffine, K, y Sheehan, K., (Eds.) (2009).

3. Nos referimos particularmente a la misión geodésica organizada por la monarquía ibérica y francesa entre 1735 y 1746, y que será analizada en el tercer apartado de este artículo.

4. Para Marie Louise Pratt, la emergencia de un nuevo tipo de "conciencia planetaria" estuvo marcada por una orientación hacia la exploración interior y la construcción de un saber a escala global a través del aparato descriptivo de la historia natural (Pratt 1992, p. 15).

5. Al regreso de su viaje, Pernety dejó los hábitos y, bajo la protección de Federico II, se convirtió en su bibliotecario al tiempo que en encargado de la abadía de Bürgel en Turingia (Gerbi 1982, p. 105). La vida del fraile benedictino, su participación en la disputa sobre la naturaleza de América $\mathrm{y}$ sus vaivenes en materia religiosa han sido analizados en profundidad por Micheline Meillassoux-Le Cerf $(1988,1993)$ en la que resultara su tesis doctoral bajo la dirección de Pierre Chaunu y publicaciones posteriores. La figura de Pernety también ha sido analizada en su relación con De Pauw por el historiador alemán Ottmar Ette en diversos artículos y capítulos de libro (Ette 2010, 2014).

6. Más allá de que la noción de "descubrimiento" haya sido cuestionada y reemplazada por la de “invención” por el historiador mexicano Edmundo O'Gorman (2003) a fines de los años 50, la noción de "nuevo descubrimiento" o "segundo descubrimiento" de América para referirse a los viajes de exploración científicos dirigidos al interior del territorio americano en el siglo XVIII resulta útil a los fines del presente trabajo. 
7. La influencia de la llamada "leyenda negra" y en términos generales la propaganda antiespañola digitada por las naciones protestantes contra la monarquía católica ha sido trabajada por autores como Frank Lestringant $(1993,1994)$ y Nicolás Kwiatkowski (2014) para los casos de Francia e Inglaterra respectivamente. Véase también García Cárcel, R. (1998).

8. Disertación sobre América y los americanos, contra las investigaciones filosóficas de M. de $\mathrm{P}^{* * *}$.

9. Véase para ello http://gallica.bnf.fr/ark:/12148/bpt6k1065220t.r=pernety+dissertation.langEN y https://archive.org/details/cihm_51345.

10. En su Défense, De Pauw especifica, por ejemplo, que las hipótesis sobre la degeneración de América debían asociarse al momento de su descubrimiento y a la América contemporánea a su tiempo.

11. Para el caso americano se destacan los aportes de Mauricio Nieto Olarte (2007), quien ha analizado en detalle el papel de la prensa periódica en el Virreinato de Nueva Granada.

12. Esta edición llevó el título completo de: Recherches philosophiques sur les Americains ou Mémoires intéressants pour servir a l'Histoire de l'Espece humaine, par Mr. de P., Avec une Dissertation sur l'Amérique et les Americaines para Dom Pernetty.

13. Sobre la conformación de la colección de viajeros del Museo Etnográfico y los intereses de la élite letrada en la Argentina del siglo XIX y principios del XX véase Raimondo, F. (2013).

14. El formato pequeño de la edición indica que al igual que las obras literarias, tratados de divulgación $\mathrm{u}$ ediciones de clásicos griegos y latinos, las obras de controversia también eran editadas para ofrecerse a menor valor que los libros en folio (gran formato) y ser más manejables para el lector.

15. Entre ellos se destaca la crítica que el abate holandés hace del clima, las características físicas y costumbres de los habitantes, la fertilidad del suelo, la degeneración de su flora y fauna y la inexistencia de los llamados "gigantes patagones" (Martínez 2011, p. 198-200).

16. Antonello Gerbi considera que la táctica contraofensiva utilizada por Pernety no es sin embargo efectiva, puesto que citar extensos fragmentos de los relatos de cronistas y viajeros para oponerlos a los dichos de De Pauw no es ejercer en realidad ninguna crítica, "sino tomar a la letra y admitir sin discriminar todo cuanto han dicho de bueno sobre el continente americano" (Gerbi 1982, p. 120).

17. La disputa entre el grado de conocimiento que podía aportar el viajero-testigo frente al saber del cosmógrafo de gabinete data en realidad del siglo XVI. Para el caso francés, el enfrentamiento entre el pastor hugonote Jean de Léry y el cosmógrafo André Thevet en torno a la validez de las descripciones de uno y otro sobre la "Francia Antártica" (1555-1560) resulta un claro ejemplo de ello.

18. "Para los viajeros el afán por acreditarse como testigos de primera mano llegó a constituir una verdadera obsesión. Las introducciones y prólogos de sus relaciones están repletas de fórmulas al uso: invocaciones al testimonio directo, a la verdad y a la ciencia, al género humano, al progreso, a la nación como equivalente de la autenticidad de un testimonio..." (Pimentel 2003a, p. 64).

19. Histoire d'un voyage aux Isles Malouines, fait en 1763 \&1764; avec des observations sur le Détroit de Magellan et sur les Patagons. Un ejemplar de la edición de 1770, publicada en dos tomos, se encuentra actualmente en la Biblioteca del Museo Etnográfico "Juan B. Ambrosetti" de la Ciudad de Buenos Aires además de encontrarse digitalizada en numerosos repositorios online. A su vez, la obra fue traducida al español y publicada recientemente en el marco de la Colección Reservada del Museo del Fin del Mundo. Véase el listado bibliográfico.

20. El contraste con las apreciaciones que De Pauw realiza sobre la flora y los habitantes de América en sus Recherches philosophiques... es evidente (De Pauw 1768, p. 4, 11). 
21. Tal como ha señalado Neil Safier, esta necesidad de hacer constante énfasis en la objetividad de lo narrado resulta un aspecto característico de todo relato de viaje publicado en el siglo XVIII (Safier 2008, p. 94).

22. Sobre el descrédito del que gozaban las fuentes españolas en la opinión de otras naciones, Juan Pimentel ha señalado: "Con frecuencia los ingleses tomaban por supercherías las noticias recogidas por los españoles; los españoles veían en los ingleses una nación de piratas y comerciantes deseosos de apropiarse de sus tesoros; los franceses tomaban en cierta consideración a los primeros y menospreciaban a los segundos como un pueblo sin luces, los habitantes del Nuevo Mundo -en fin- solían quejarse de que en realidad ni unos ni otros sabían de lo que hablaban" (Pimentel 2003a, p. 64).

23. Es probable que al hablar de los "antiguos autores españoles" Pernety se refiera a las crónicas de Gonzalo Fernández de Oviedo pero también a las "cartas edificantes" de los misioneros, criticadas por De Pauw en sus Recherches philosophiques... (1768, p. X)

24. Es probable que por cuestiones de acceso, disponibilidad y circulación Pernety haya hecho mayor alusión a autores y experiencias de colonización francesas que a las de otras naciones. En efecto, la referencia a Bristock, tal como lo señala el autor, es tomada de la Histoire Naturelle et Morale des Antilles (1658) de Charles de Rochefort.

25. Para un análisis en profundidad de la llamada retórica de la alteridad véase Hartog, F. (2003).

26. Sobre la hospitalidad expresada por los tupinambás, con los cuales Léry convive por un tiempo, véanse los capítulos XVIII y XIX de la Histoire d'un voyage fait en la terre du Bresil, autrement dite Amérique (Martínez 2013).

27. De Pauw llega incluso a "corregir" las aseveraciones de Buffon para América en las páginas 23, 197, 307, 312 del Tomo I de Recherches philosophiques sur les Américains..., Berlín, 1770.

28. Más allá de los objetivos impuestos por la Corona, los intereses de ambos viajeros distaron, sin embargo, de ser semejantes: al espíritu empresarial y práctico de Frézier se contraponía la figura más docta de Feuillée, astrónomo erudito e historiador natural (Cañizares Esguerra 2007, p. 42).

29. Es probable que Pernety haya tenido acceso a los tres tomos del Journal des observations physiques, mathematiques et botaniques, faites par l'ordre du Roy sur les côtes orientales de l'Amérique meridionale, \& dans les Indes occidentales, depuis l'année 1707 jusques en 1712. Par le R. P. Louis Feuillée, religieux minime, mathematicien, botaniste de Sa Majesté, \& correspondant de l'Académie royale des sciences. Los dos primeros fueron publicados en 1714 y el tercero en 1725 . Una copia de los mismos puede hallarse en la biblioteca del Museo Mitre de la ciudad de Buenos Aires, que conserva una importante colección de relatos de viaje pertenecientes al estadista.

30. En el caso de Frézier se trata de la Relation du voyage de la mer du Sud aux côtes du Chily et du Pérou, fait pendant les années 1712, 1713 et 1714..., publicada por primera vez en París en 1716.

31. Además de exaltar la figura del viajero francés que ha permanecido seis años en América, en esta última obra De Pauw llega incluso a acusar a Pernety de no haber leído el relato de viaje de La Condamine (De Pauw 1770b, T. 3, p. 35).

32. Para un estudio detallado de la recepción que mereció la Relation abrégée (1745) de La Condamine tanto en el mundo académico como dentro de la prensa periódica véase Safier, $\mathrm{N}$. (2008). Measuring the New World. Enlightenment Science and South America. Chicago y Londres: The University of Chicago Press, Capítulo 3: "Armchair explorers".

33. En 1738 Maupertuis publica su Relation du voyage fait au cercle polaire y en 1752 sus Lettres sur le progrès des sciences.

34. Esto no implicó, sin embargo, que sus apreciaciones no fueran cuestionadas por filósofos y exploradores europeos y americanos (Safier 2008, p. 99).

35. Aparece aquí la importancia de la República de las Letras en el siglo XVIII como una comunidad letrada de iguales que, a través de la correspondencia y colaboración entre pares, las publicaciones científicas, los viajes exploratorios y las conversaciones eruditas, comparte valores 
y establece consensos respecto de la totalidad del saber. Para un estudio exhaustivo de la noción desde sus orígenes en el siglo XVI hasta el siglo XVIII véase Waquet (1989).

36. En la opinión de Garrison Brinton, Bristock pudo haber creado un relato a partir de historias fragmentadas y leyendas escuchadas en el transcurso de su estadía en esa región de América (Garrison Brinton 1859, p. 98).

37. Al respecto, véase el análisis propuesto por Juan Gil Fernández (1989) en torno a las motivaciones y mitos detrás de las distintas expediciones a América.

38. "Y allí salió a nosotros vn señor que le tarýa un indio acuestas [...] y por señas le dimos a entender que ýbamos a Apalache, y por las que él hizo nos paresció que era enemigo de los de Apalache, y que nos yría a ayudar contra él." (Núñez Cabeza de Vaca 1992, p. 196) O "Con este trabajo caminamos hasta vn día después de Sant Juan, llegamos a vista de Apalache, sin que los indios de la tierra nos sintieran. Dimos muchas gracias a Dios por vernos tan cerca dél creyendo que era loq ue de aquella tierra nos auían dicho, que allí se acabarían los grandes trabajos que aúamos pasado [...] Más con vernos llegados donde deseáuamos y donde tanto mantenimiento y oro nos auían dicho que auía, paresciónos que se nos auía quitado gran parte del trabajo y cansancio." (Núñez Cabeza de Vaca 1992, pp. 197-198)

39. La transformación que aquí se destaca es similar a la que opera respecto de la noción de "buen salvaje", cuyas connotaciones cambian entre el siglo XVI y XVIII (Lestringant, 1993).

40. En el original en francés, la frase termina sin el signo de interrogación. Sin embargo, puesto que se trata de una pregunta, hemos decidido agregarlo.

41. Para una comprensión más clara del sentido, a esta frase también se le han agregado signos de interrogación.

42. La cursiva es nuestra.

43. La cursiva es nuestra. El autor se refiere a los Montes Apalaches, cadena montañosa ubicada al este de los actuales Estados Unidos que llega en su parte meridional hasta el estado de Alabama. Pánfilo de Narváez y Hernando De Soto, sin embargo, dicen haber encontrado a los apalaches en sus incursiones a la península de Florida.

44. La cursiva es nuestra. Este era el nombre de los sacerdotes de los apalaches, tal como lo indica Brinstock en su propia crónica.

\section{ABSTRACTS}

The dispute over the nature of the New World that took place in Europe towards the end of the 18th century not only confronted the defenders of what was considered the privileged nature of the New World and its inhabitants to those who proposed a degenerate image of America, but also encouraged the reevaluation of the criteria that had been used so far to assess the reliability of the sources. The loss of credibility experienced by Spanish chroniclers, whose first impressions on the newly discovered lands were now judged as implausible and unreal, enabled the development of new ways of perceiving the nature of America, as can be observed in the works of former Capuchin Antoine-Joseph Pernety. In open opposition to the harshest criticisms on the nature of America made by Cornelius De Pauw, Pernety used his own experience in America and that of fellow travelers to praise its fauna, flora and its inhabitants. In light of the above, this article analyzes the historical context and the mechanisms by which Pernety argues against De Pauw and, in so doing, deconstructs the postulates defended by the latter. Special emphasis will 
be made on a fragment of his Dissertation on America and Americans, published in 1770 and translated into Spanish for the first time in this article.

El debate sobre la naturaleza del Nuevo Mundo que tuvo lugar en Europa hacia fines del siglo XVIII no solamente enfrentó a los defensores de la naturaleza privilegiada del Nuevo Mundo y de sus habitantes contra aquellos que proponían una imagen degenerada de América, sino que llevó a una reevaluación de los criterios más tradicionales utilizados hasta entonces para evaluar la confiabilidad de las fuentes. La pérdida de credibilidad de los primeros cronistas españoles, cuyas impresiones sobre las tierras descubiertas comenzaron a ser juzgadas como inverosímiles y fantasiosas, permitió articular entonces nuevas miradas sobre el carácter de América. En efecto, en abierta oposición a las críticas más acérrimas en torno a la naturaleza americana realizadas por Cornelius De Pauw, en la obra de Antoine-Joseph Pernety que aquí se presenta puede observarse cómo el benedictino se escudó en su experiencia como viajero a aquellas tierras para, a partir de sus propias vivencias y las de viajeros contemporáneos, articular un discurso laudatorio de su fauna, flora y habitantes. En función de lo antedicho, el presente artículo analiza el contexto de producción y los mecanismos a través de los cuales Pernety argumenta contra los postulados de De Pauw para así deconstruir los presupuestos de este último. Se hará particular hincapié en un fragmento de su Disertación sobre América y los americanos, publicado en 1770 y traducido aquí por primera vez al castellano.

INDEX

Keywords: Pernety, dispute, nature, America

Palabras claves: Pernety, disputa, naturaleza, América

\section{AUTHOR}

\section{CAROLINA MARTÍNEZ}

Universidad de Buenos Aires, Universidad de Paris 7 Denis Diderot, Consejo Nacional de Investigaciones Científicas y Técnicas, Argentina.

Correo electrónico: cmartinez79@gmail.com 